Article

\title{
Social Life-Cycle Assessment: A Review by Bibliometric Analysis
}

\author{
Irene Huertas-Valdivia ${ }^{1, *(\mathbb{D}}$, Anna Maria Ferrari ${ }^{2}$, Davide Settembre-Blundo ${ }^{1,3}$ \\ and Fernando E. García-Muiña ${ }^{1}$ (D) \\ 1 Department of Business Administration (ADO), Applied Economics II and Fundaments of Economic \\ Analysis, Rey-Juan-Carlos University, 28032 Madrid, Spain; davide.settembre@urjc.es (D.S.-B.); \\ fernando.muina@urjc.es (F.E.G.-M.) \\ 2 Department of Sciences and Methods for Engineering, University of Modena and Reggio Emilia, \\ 42122 Reggio Emilia, Italy; annamaria.ferrari@unimore.it \\ 3 Gruppo Ceramiche Gresmalt, Via Mosca 4, 41049 Sassuolo, Italy \\ * Correspondence: irene.huertas@urjc.es; Tel.: +34-914-887-795
}

Received: 2 July 2020; Accepted: 22 July 2020; Published: 1 August 2020

\begin{abstract}
This study examined the literature on social life-cycle assessment (S-LCA) published in the last 15 years (2003-2018) using bibliometric methods. Applying scientific mapping and analyzing publication performance, the study describes the structure of and trends in S-LCA publications in terms of related subject categories, authors, journals, countries, and highly cited articles. Challenges and research gaps in the S-LCA literature were also explored. The content of related papers published in the ISI Web of Science databases was examined to identify the main themes investigated, evolution of publication activity, and most representative elements. Analyses were conducted with SciMAT software. This tool enables researchers to map research specialties by extracting qualitative information in the specialized literature and representing it using quantitative measures. The results show rapid and exponential growth of the S-LCA research line in the past ten years, with a clear upward trend in related publications (mostly case studies), especially after publication of the UNEP/SETAC Guidelines for Social Life Cycle Assessment of Products in 2009: 66\% of all articles published on S-LCA were published during the period 2015-2018, primarily by European authors. The findings also delineate S-LCA as a highly fragmented research field that has been applied to diverse sectors (agriculture, bioenergy, transport, water management, chemical products, electronics, etc.), mainly in non-European countries. Critical questions concerning methods, framework, paradigms, and indicators remain to be resolved. This study provides insight into the publication performance of S-LCA, characterizing its intellectual structure and salient authors and works. In identifying hotspots in the S-LCA research, the study provides a useful state-of-the-art reference guide for academics and reveals critical research gaps and potential research avenues for future studies to advance in consolidating the discipline.
\end{abstract}

Keywords: Social Life-Cycle Assessment (S-LCA); bibliometric methods; science mapping; co-word analysis; social impacts

\section{Introduction}

Within the framework of sustainable development, the "social pillar" of sustainability has attracted increasing attention in recent decades. Social life-cycle assessment (S-LCA) is "a technique for collecting, analyzing and communicating information about the social conditions and impacts associated with production and consumption" [1] (p. 6974). S-LCA focuses on current and potential (positive and negative) socio-economic impacts of processes, products, and services throughout their full life cycle [2] The ultimate goal of conducting S-LCA is to provide decision-making support after evaluating changes 
in the lives of workers, consumers, society, and other key stakeholders related to the product's life cycle. S-LCA helps decision-makers to choose the alternatives with the most favorable social consequences.

Since publication of the United Nations Environment Programme (UNEP) and the Society for Environmental Toxicology and Chemistry's (SETAC) UNEP/SETAC Guidelines in 2009 [3], S-LCA of products and services has received growing attention. S-LCA is an important emerging field of study, and several recently published theoretical and methodological works advance understanding of the methodology's application in different sectors. Despite growing interest in this field, the body of literature remains small. Most published research is case-study-specific and based predominantly on qualitative or semi-qualitative data, making it difficult to infer from results to general situations. More work is needed to address the complexity of S-LCA.

Advancing a research field initially requires a deep understanding of the work published in the field to consolidate the concepts and variables investigated. Understanding the foundations enables researchers to identify potential new research directions and methods to complement, improve, and build on previous work. Although scholars have traditionally conducted qualitative structured literature reviews to obtain a state-of-the-art picture of a field's evolution and current situation, narrative literature reviews may be biased by the researcher's criteria, compromising scholarly rigor.

In recent years, academia has increasingly used science mapping to establish the structure and development level of scholarly disciplines accessible in online databases [4]. Based on bibliometric methods, science mapping provides visual classification of the structure of a specific research area, enabling researchers to detect the most influential works, authors, journals, etc. Also known as bibliometric mapping, science mapping helps to display the structural and dynamic aspects of scientific research through representations of intellectual connections within the field of knowledge [5]. Such visual spatial representation allows researchers to identify key relationships among authors, disciplines, fields, references, etc., as well as the longitudinal evolution of research topics. Since science mapping adopts a macro focus, it can analyze both the general conceptual structure and the main concepts treated in a field of study.

The purpose of this investigation is to understand the scientific structure and dynamics of S-LCA by applying bibliometric methods. The study will enable academics to answer the following research questions:

- RQ 1-What literature is relevant to this research field in terms of main publications and key authors?

- $\quad$ RQ 2-What specific research subjects are related to S-LCA?

- RQ 3-How has this topic evolved in recent years?

- $\quad$ RQ 4-What emerging fields and research gaps are associated with S-LCA studies?

While some previous studies provided state-of-the-art approaches in the scholarly development of S-LCA, they focused on very specific plots, as shown in Table 1. For example, a critical literature review by Iofrida et al. [6] determined the underlying paradigms applied in 133 S-LCA papers from 1996 to 2015; Sureau et al. [7] identified 14 distinct S-LCA frameworks in their comparative review; and Di Cesare and her colleagues [8] focused on defining positive impacts in the S-LCA literature and its indicators. 
Table 1. Previous papers on the state-of-the art of social life-cycle assessment (S-LCA).

\begin{tabular}{|c|c|c|c|c|}
\hline Authors \& Year of Publication & Number of Papers Reviewed & Period & $\begin{array}{l}\text { Research Question/ } \\
\text { Purpose of the Study }\end{array}$ & Technique/Methods \\
\hline $\begin{array}{l}\text { Arcese, Lucchetti, Massa, \& Valente (2018) } \\
\text { [9] }\end{array}$ & 51 & 2006-2014 & $\begin{array}{l}\text { To classify contributions on S-LCA (approaches and } \\
\text { development of themes) }\end{array}$ & $\begin{array}{c}\text { Automatic text analysis tools (TaLTaC2) } \\
\text { (lexicon analysis, principal component analysis) }\end{array}$ \\
\hline Bonilla-Alicea \& Fu (2019) [10] & 81 articles published in English & 2009-2019 & $\begin{array}{l}\text { To determine: How many case studies were published } \\
\text { between } 2009 \text { and } 2019 ? \\
\text { What are the areas of application and main challenges } \\
\text { of social impact assessments? }\end{array}$ & $\begin{array}{l}\text { Systematic mapping and systematic review of } \\
\text { Scopus database and Google Scholar }\end{array}$ \\
\hline $\begin{array}{l}\text { Di Cesare, Silveri, Sala, \& Petti (2018) } \\
\text { [8] }\end{array}$ & $\begin{array}{l}47 \text { papers (theoretical) } \\
+46 \text { case studies }\end{array}$ & $\begin{array}{l}\text { Based on Petti et al. (2014) } \\
\text { systematic review + those } \\
\text { published until June } 2015\end{array}$ & $\begin{array}{l}\text { To understand definitions of positive impacts in the } \\
\text { literature and its indicators }\end{array}$ & Systematic literature review \\
\hline $\begin{array}{l}\text { Iofrida, De Luca, Strano, } \\
\text { \& Gulisano (2018) } \\
\text { [6] }\end{array}$ & 133 & 1996-July 2015 & $\begin{array}{l}\text { To determine which underlying paradigms have been } \\
\text { applied in S-LCA literature (boundaries between } \\
\text { paradigms) }\end{array}$ & Critical review \\
\hline $\begin{array}{c}\text { Jørgensen (2013) } \\
{[11]}\end{array}$ & - & - & $\begin{array}{l}\text { To identify main characteristics and use of S-LCA, } \\
\text { highlighting its unique features }\end{array}$ & Review of 10 years of S-LCA literature \\
\hline $\begin{array}{c}\text { Jørgensen, Le Bocq, Nazarkina, \& } \\
\text { Hauschild (2008) } \\
\text { [12] }\end{array}$ & $\begin{array}{l}\text { Journal papers, conference } \\
\text { proceedings and reports }\end{array}$ & Publications up to 2008 & $\begin{array}{l}\text { To identify general points of agreement and } \\
\text { disagreement among authors. } \\
\text { Focuses on methodological shortcomings }\end{array}$ & Thorough literature survey \\
\hline $\begin{array}{c}\text { Mattioda, Mazzi, Canciglieri, } \\
\text { \& Scipioni (2015) } \\
\text { [13] }\end{array}$ & $\begin{array}{l}99 \text { papers obtained after } \\
\text { a qualitative } \\
\text { bibliographical survey conducted in } \\
\text { two databases }\end{array}$ & 2010-2013 & $\begin{array}{l}\text { To determine the principal references and authors on } \\
\text { S-LCA } \\
\text { (Identifies } 524 \text { references } \\
\text { used in } 56 \text { journals and by } 358 \text { authors) }\end{array}$ & $\begin{array}{c}\text { Literature review in } \\
\text { Italian database AIRE } \\
\text { (http://www.cab.unipd.it/node/36) } \\
\text { and Brazilian } \\
\text { CAPES Database } \\
\text { (http:www.periodicos.capes.gov.br) }\end{array}$ \\
\hline $\begin{array}{l}\text { Sureau et al. (2018) } \\
\text { [7] }\end{array}$ & $\begin{array}{l}\text { A number of existing literature } \\
\text { reviews and additional publications, } \\
\text { conference proceedings, and } \\
\text { consultancy websites }\end{array}$ & Not specified & $\begin{array}{l}\text { To provide a more comprehensible picture of S-LCA } \\
\text { frameworks. } \\
\text { Identifies and classifies } 14 \text { distinct S-LCA frameworks }\end{array}$ & Comparative review based on the literature \\
\hline
\end{tabular}


In a systematic map of the field of social impact assessment based on 81 articles, Bonilla-Alicea and $\mathrm{Fu}$ [10] detected 12 fundamental challenges in research on the topic. Most of these literature reviews were, however, conducted using a systematic approach [14], providing a critical review [6,11], employing different qualitative methods, or focusing on a single or limited number of journals. A review of S-LCA based on bibliometric techniques is needed because the bibliometric method for reviewing and evaluating scientific literature can "complement meta-analysis and qualitative structured literature reviews" [4] (p. 429).

Prior to this study, other authors $[15,16]$ conducted bibliometric analyses to examine life-cycle assessment (LCA). Most recently, Ramos Huarachi and his colleagues [17] employed VOSviewer software to analyze the most significant S-LCA literature, identifying the historical evolution of the concept (distinguishing four stages of research) and highlighting the main frameworks for social life-cycle impact assessment (SLCIA) methods (type I and type II). These authors assert that "there is still a long way ahead to achieve scientific maturity" in S-LCA and strongly recommend continuing research on themes in S-LCA and social sustainability [17] (p.1). Our paper thus aims to provide an objective supplement to prior evaluations of the literature through visual classification of the main topics, authors, and journals on S-LCA. This novel scientific mapping analysis will enable scholars to distinguish key areas of interest and, we hope, encourage further development of the field.

Our paper contributes to the research field of S-LCA in two ways. First, with the assistance of bibliometric techniques, the paper quantitatively evaluates the rapidly growing literature on S-LCA in the last decade, enabling researchers to track significant literature in this field. By highlighting the key authors and main journals that specialize in S-LCA, this paper guides researchers to the most influential works in the literature. Second, the paper uses a co-word analysis technique to identify emerging, maturing, and decadent topics in the S-LCA literature. The findings can orient new research on S-LCA by encouraging further investigation of key emerging themes and areas that have received insufficient study in the past. Moreover, the paper's detailed explanation of its methodological steps is useful for researchers who wish to perform bibliometric analysis of their fields of interest. Our paper is a good starting point for young scholars who seek better understanding of S-LCA as a research field and familiarity with scientific mapping analysis.

This paper is structured as follows. The first section provides an overview of the topic, orienting the reader to the field of S-LCA. The method section describes the research protocol, software, data examination, and co-word analysis technique. Next, the results section details S-LCA publication activity, identifying its patterns, S-LCA authors' performance, and key related publications by journal, author, and country. Subsequently, related topics and salient themes associated with S-LCA, and main areas of research (by sector, country, and stakeholder), are identified. The discussion section presents and debates the findings, highlighting research advances in the standardization of assessment steps, and in the identification and inclusion of stakeholders. The conclusion interprets issues to be resolved regarding theoretical framework, research paradigms, standardized indicators, and social impact measures. The conclusion highlights the study's implications and current limitations.

\section{Literature Review}

\subsection{Emergence of S-LCA as a Research Topic}

During the 1990s, LCA experts emphasized the need to discuss and begin to consider the social welfare impact of production [18,19]. In 2002, the "Life Cycle Initiative" (https://www.lifecycleinitiative. org/) was launched by the partnership of the United Nations Environment Programme (UNEP) and the Society for Environmental Toxicology and Chemistry (SETAC) in response to the call to foster a life-cycle economy (to promote sustainable consumption and production patterns). The initiative's main purpose was to enable users to put life-cycle thinking into practice worldwide by facilitating exchange of knowledge and creation of life-cycle networks. Debate arose about the need to create specific categories to evaluate social, as distinct from environmental, criteria. 
In this context, the Project Group on an S-LCA started its work in 2004, seeking to include social issues in sustainable development tools. Several scholars attempted to bridge the gap between business ethics and LCA by expanding the LCA methodology beyond merely quantifying potential environmental impacts of a product system's energy and material consumption. Aiming to integrate companies' social performance, Dreyer et al. [20], Gauthier [21], and others suggested improvements to "extend" LCA to the social dimension. Understanding the importance of broadening existing impact assessment studies, the UNEP/SETAC partnership analyzed and published a description of different practices to measure S-LCA in 2009. These Guidelines for Social Life Cycle Assessment of Products [3] provided a map of action for practitioners interested in assessing the social and socio-economic impacts of a product's life cycle. Some years later, the Methodological Sheets for Subcategories in Social Life Cycle Assessment [22] complemented the Guidelines by providing methodological hints for each stakeholder subcategory and including examples of inventory indicators, units of measurement, and potential data sources for hotspot assessment.

Nevertheless, S-LCA of products has frequently been "overlooked due to the difficulty of its definition and the even greater difficulty of its implementation" [13] (p. 1156).

\subsection{Fundamentals of $S-L C A$}

S-LCA is based on a combination of reference methods, representation models, and data about the product system and its current and potential impacts. "Since S-LCA has not yet been formalized in an international standard," it follows the steps proposed by ISO 14,040 for environmental LCA [23] (p.5). Like the LCA framework, S-LCA is composed of four phases: (1) setting the goal of the study (e.g., product, process, or company comparisons, or product or process improvement potentials) and defining its scope (object of study), (2) data inventory (collecting data and significant information), (3) impact assessment (assigning inventory results to impact categories and subcategories), and (4) interpretation of results.

S-LCA principally assesses potential social impacts: the probable positive or negative consequences for human well-being of organizations' activities or behaviors linked to use of the product or to its production life cycle. Potential social impact can be evaluated by assessing social performance (organizations' deliberate actions towards stakeholders and unintended externalities of business activities) and social risk (likelihood of adverse social effects on stakeholders due to business-related activities). Such assessment is of great utility when comparing, for example, social performance of different products, sectors, or energy sources. It thus constitutes a helpful tool in policy-making, company reporting, and resource allocation and management, among other areas [1].

Iofrida et al. [24] identified three main types of methods developed to assess impact: (1) methods inspired by the UNEP/SETAC Guidelines and Methodological Sheets (based on stakeholder groups and possible impact categories, subcategories, and indicators); (2) studies from a social impact pathways perspective, following an epistemological approach similar to environmental life-cycle assessment (E-LCA); (3) and the capacities/capabilities approach, based on identifying variations in capital stocks caused by a product's life cycle.

Impact assessment, or S-LCIA, follows two main approaches, known as type I and type II [25]. Type I (reference scale approach) helps to describe past or current states of an existing product system, with focus on its social performance of social risk. It relies on data to estimate the likely magnitude and significance of potential social impacts down the line and analyzes organizations' behavior based on performance reference points. In line with E-LCA, type II (impact pathway approach) predicts the consequences of current or future states of an existing or non-existent product system in the long run, establishing causal or correlation-based relationships among variables [25]. Some authors recommend combining type I and type II assessments [7].

Unlike environmental impact indicators, many social impact indicators are difficult to quantify [26]. Due to the complexity of finding accurate and objective proxies for social indicators, no unanimity exists on what impact categories to include or how to measure some impacts. In fact, many authors 
supplement the impacts in the UNEP/SETAC Guidelines with additional ones [27]. Some authors [26] rank impact categories and subcategories by importance, surveying a panel of experts by questionnaire and using their responses to calculate the weight of each criterion. Authors such as Jørgensen et al. [12] provide a list of social impact categories and midpoint indicators, including number and type of indicator (qualitative and quantitative) for each impact category. Analyzing 46 case studies in detail, some of which were tailored to the specific research goal, Di Cesare et al. [8] identified 569 indicators ( $57 \%$ of them semi-quantitative, $18 \%$ quantitative, and $25 \%$ qualitative). These authors also observed that the indicators proposed by the UNEP/SETAC Methodological Sheets [22] were barely considered in non-site-specific impact assessments. More recently, "important social indicators such as human health impacts, employment, accidents and safety, public acceptance, life expectancy, public welfare and equity" are used quantitatively in S-LCA of, for example, energy and transportation systems [28] (p. 15).

Applicability of S-LCA is sometimes limited by the need for and difficulty of quantifying data, and the subjective nature of some social indicators [28]. In fact, debate is growing in the S-LCA literature over data collection methods and the use of generic data assessment (industry averages, typical conditions, national examples), such as the use of databases or sources of statistical data vs. case-specific data retrieved on site [12,29]. Data collection (inventory step) is frequently the most labor-intensive step of any S-LCA. Different institutions have made several LCA databases availableto help environmental practitioner assessment (for a list, see https://nexus.openlca.org/). Some specialize in specific sectors, such as agriculture and food (e.g., Agri-footprint, Agribalyse, ESU World Food, USDA) or energy-related supply chains (e.g., ecoinvent, NEEDS, ProBas). However, few databases were developed specifically to calculate and assess social impacts of products throughout their life cycles. The Social Hotspot Database (SHDB) (https://www.socialhotspot.org/) and Product Social Impact Life Cycle Assessment Database (PSILCA, https://psilca.net/), for example, contain key social indicators to address different stakeholder groups.

Based on the UNEP/SETAC Guidelines, the SHDB [30] is one of the most common sources in the S-LCA literature for assessing social impacts, as it identifies social risks for over 100 indicators. The SHDB includes a global input/output model, a worker-hours model ("using annual wage payments and wage rates by country and sector"), and "social theme tables covering 22 themes" [1] (p. 6973). Using an additive weighting method based on both worker-hour intensity and risk levels across multiple social themes, the $S H D B$ calculates Social Hotspot Indexes. The database estimates the functional unit for worker-hour modeling by the number of work-hours the different supply-chain agents need to deliver an output of 1 million dollars' worth of a specific product. Characterization models then enable global comparison of country-specific sectors based on four risk levels: low (0), medium (1), high (2), and very high (3). The SHDB estimation has been applied in many diverse studies, including resource recovery from wastewater [31] and brine treatment [32], among others [27]. To overcome lack of sector-specific data for some indicators, authors sometimes complement results with literature content analysis [33] or complement the SHDB with other data sources (e.g., International Trade Centre or United Nations Commodity Trade Statistics) [31].

Another database used in S-LCA studies is PSILCA [34], developed by the consultancy Greendelta. Based on the multi-regional input/output (MRIO) database Eora, PSILCA provides data for around 15,000 sectors and 189 countries. (Further information at https://www.openlca.org/wp-content/ uploads/2016/08/PSILCA_documentation_v1.1.pdf). Moreover, organizations such The Sustainability Consortium (https://www.sustainabilityconsortium.org/) develop dossiers for different products by categorizing their sustainability profiles and stakeholder-related issues. Indexes like the Social Progress Index (https://www.socialprogress.org/) also serve as potential measures for S-LCA models.

Based on PSILCA and ecoinvent, SOCA is the first database to attempt to provide complete comprehensive S-LCA, complementing environmental and cost data with social risk information (https://nexus.openlca.org/database/soca). The main limitation of all of the general databases mentioned is the fact that the information is collected primarily at country or sector level and does not register 
regional or local particularities. Further, as most of these databases charge a high fee for use, researchers diverge in their views on use of generic data.

In sum, the usefulness of S-LCA lies in its ability to solve or mitigate certain problems, and its ultimate goal is to promote improvement of the social conditions of the stakeholders involved and affected [29].

\section{Methods}

Bibliometric analysis was chosen because it enables the "study [of] science as a knowledge-generating system," providing indicators to assess the specific scientific production in a research field over a specific period of time [35] (p. 454). Since a scientific mapping methodology is very appropriate, we performed co-word analysis of the concept S-LCA with Science Mapping Analysis Tool (SciMAT, available at: https://sci2s.ugr.es/scimat/) software [36] in the Web of Science (WoS) database. SciMAT was chosen because it has useful pre-processing capabilities for data cleaning, builds science maps enriched with different bibliometric measures, and enables longitudinal framework analysis.

Like other similar bibliometric tools, SciMAT analyzes the raw bibliographic data exported (in this case, from WoS), and calculates similarity matrices between items (documents, words, etc.). Table 2 summarizes the workflow followed.

Table 2. Workflow followed to conduct science mapping.

\begin{tabular}{|c|c|c|}
\hline Step 1. & Research design & $\begin{array}{l}\text { (a) Research question: What is the knowledge base structure of the topic S-LCA? } \\
\text { (b) Selection of co-word analysis method }\end{array}$ \\
\hline Step 2. & $\begin{array}{l}\text { Compilation of } \\
\text { bibliometric data }\end{array}$ & $\begin{array}{l}\text { (a) Selection of appropriate database: ISI Web of Science (Social Science Citation } \\
\text { Index, Science Citation Index Expanded, Arts \& Humanities Citation Index, } \\
\text { Emerging Sources Citation Index) } \\
\text { (b) Search criteria: ("S-LCA" or "Social life-cycle assessment" or "SLCA" or } \\
\text { Social-LCA") in English (articles up to and including 2018) } \\
\text { (c) File pre-processing: filtering of core document set and exportation of } \\
\text { bibliographic data (.txt) }\end{array}$ \\
\hline Step 3. & Analysis & $\begin{array}{l}\text { (a) Choice of appropriate bibliometric software: SciMat } \\
\text { (b) Data cleaning: removal of } 86 \text { documents wrongly included in the compilation } \\
\text { due to wording similarities } \\
\text { (c) Selection of unit of analysis (words) and matrix type (co-occurrence matrix); } \\
\text { network reduction, normalization, and clustering algorithm } \\
\text { (d) Identification of document subgroups that represent research specialties }\end{array}$ \\
\hline Step 4. & Visualization & (a) Choice of visualization method: cluster and network analysis \\
\hline Step 5. & $\begin{array}{l}\text { Interpretation and } \\
\text { discussion of results }\end{array}$ & $\begin{array}{l}\text { (a) Network of themes and their relationships that represent the conceptual space } \\
\text { of S-LCA } \\
\text { (b) Determination of knowledge base (set of articles and authors most cited by } \\
\text { current research; identification of top journals) }\end{array}$ \\
\hline
\end{tabular}

\subsection{Database Selection and Research Protocol}

The database selected was the ISI Web of Science (Social Science Citation Index, Science Citation Index Expanded, Arts \& Humanities Citation Index, and Emerging Sources Citation Index). This database is the most common source of bibliographic data because it contains data sufficient and suitable for bibliometric analysis, and is available in most university subscriptions [4]. Some researchers argue that this database is the most important source of data for bibliometric analysis in the sciences and that its records are more consistent, detailed, and standardized than, for example, Scopus $[15,16]$.

The scope of the study was established by the search protocol with the following search string: Social life-cycle assessment, S-LCA, SLCA, and Social-LCA in the title, abstracts, and keywords of peer-reviewed articles published up to and including 2018 [9]. The search returned 273 articles. The bibliographic data containing key information (title, authors, journal, abstract, and keywords) were exported in a .txt file and then imported into SciMAT [36] for further analysis. 


\subsection{Data Pre-Processing}

Firstly, data purification was necessary to achieve accurate results. As Zupic and Čater [4] (p. 440) observed, "even when search terms are very carefully chosen, a database search usually finds studies that are not within the scope of the review," requiring a method to examine and discard unwanted unrelated documents that might introduce outliers into the document set. To increase validity of the results, the authors reviewed all entries in the dataset to verify that each article actually investigated some aspect of S-LCA. All article titles and abstracts retrieved in the data set were inspected (and the full article skimmed in some cases) to eliminate potential bias in the results. Several documents that did not focus explicitly on S-LCA, and others with identical nomenclature (SLCA) but unrelated to LCA, were detected and removed (e.g., Smallest Lowest Common Ancestor, Single Length Cycle Attractors, Streamlined Life Cycle Assessment, Stray Light Correction Algorithm, Self-learning Cellular Automata, etc.). This appraisal of the document set produced 187 articles identified as appropriate for analysis.

The pre-processing phase also corrected for duplicate terms and misspelled words. In addition, various representations of the same concept were reduced to one form, as is desirable in co-word analysis $[4,37]$. This step identified similar words using the stemming algorithm and manually grouping them under their root form (e.g., case-study/case-studies; bioenergy/bio-energy). Similarly, authors' names were checked individually to aggregate results by the same author that the program could not identify due to dissimilarities in spelling (e.g., Benoit, Benoît, and Benoît-Norris). Further, for data preparation, researchers identified units (keywords) containing relevant information, discarding some common words in general use that introduced noise into the study (e.g., increase, key, sector). In sum, we followed the filtering process suggested by Corrales-Garay et al. [38]: (1) grouping, (2) standardization of terms, and (3) elimination of terms considered as overly general to avoid distortions in the analysis.

\subsection{Co-Word Analysis}

The main purpose of this study was to establish relationships among words in published papers to build a conceptual structure of the S-LCA research field over consecutive time periods. Since the unit of analysis was a concept (S-LCA), the most suitable technique for the various analyses was content analysis. We therefore chose co-word analysis, an advanced data-analytical technique that searches the titles, abstracts, and keywords of different documents to identify connections among concepts that often appear simultaneously. Detecting co-occurrence of the same words in different documents reveals the underlying relationship between those concepts, helping academics to understand the cognitive structure of the research field. Co-word analysis also enables scholars to identify networks of words and study their evolution over time. These word associations "reduce a publication to a series of signal words" [39] (p. 204).

Since the unit of co-word analysis is a word, a threshold of word co-occurrence must be established to measure word frequency properly. Since our study dataset was not very large (922 units), the threshold was established at a minimum frequency of two words, in line with $[38,40]$. Similarity measures were also employed to normalize the bibliometric networks (equivalence index) and build maps using clustering algorithms (simple centers algorithm) to determine strong association of sub-groups of keywords [39].

\section{Results}

SciMAT software can represent scholarly knowledge as a network system. In its visual representation of this scientific network, nodes represent keywords, authors, journals, etc., and lines show the connection or relationships between the different nodes. This spatial representation of the findings makes it easy for researchers to distinguish the conceptual, intellectual, and social network of a scientific field and its evolution over time. 


\subsection{Publication Activity on S-LCA}

Publication activity is defined as the number of papers a journal publishes in a given period of time. Mapping publication activity provides a summary of the quantitative evolution of literature on S-LCA over time, identifying the most representative journals publishing in this discipline and the most cited researchers.

Figure 1 shows the quantitative evolution of the literature on S-LCA, providing the annual totals of articles about S-LCA during the period 2003-2018. A total of 37 journals published 188 articles specifically on S-LCA themes. As Figure 1 shows, the research on S-LCA has increased rapidly in recent years, with the highest publication rate in 2018. We found considerable and growing interest in including social issues in the sustainability assessment of products after the 2009 introduction of the UNEP/SETAC Guidelines for Social Life-Cycle Assessment of Products, which provided state-of-the-art analysis of different methods of social impact assessment in the production of goods and services. Prior to this publication, S-LCA was a very new and immature field, with very few publications [12]. The first publications identified that explicitly mention "S-LCA" were Klöpffer's in 2003 and 2006 [41,42], which draw on the proposal of SELCA, in O'Brien et al. [19], a study prominent in the infancy of S-LCA studies that stresses the large research gap concerning method.

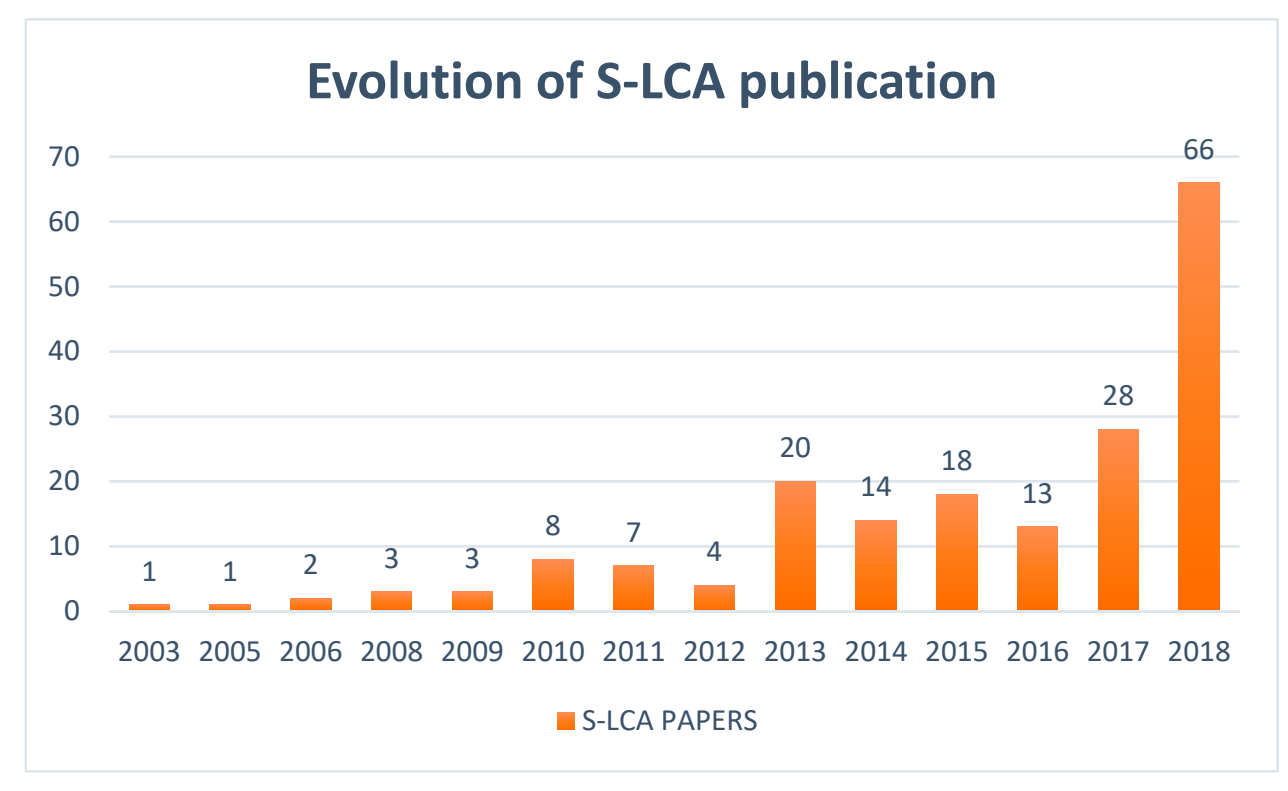

Figure 1. Evolution of S-LCA publication.

Publication activity on S-LCA begins to grow around 2013 [24], likely explained by UNEP/SETAC's publication of the Methodological Sheets for Subcategories in Social Life Cycle Assessment. The Methodological Sheets serve as a methodological guide to application of S-LCA. They provide detailed information and examples of how to conduct generic and specific analysis in 31 stakeholder subcategories (e.g., delocalization and migration, community engagement, cultural heritage, respect of indigenous rights, supplier relationships, promoting social responsibility). One of the main purposes of the Methodological Sheets was "to inspire S-LCA case studies based on the Guidelines" [22] (p. 5), as very few S-LCA case studies had previously been performed [29]. S-LCA thus gained more research attention, and publication output on S-LCA increased in academic journals, especially through case studies, as Figure 1 shows. The peak in publications on S-LCA themes occurred in 2018, probably due to the special issue Social LCA in Progress of the International Journal of Life-Cycle Assessment, with 30 papers on S-LCA.

Table 3 provides an in-depth view of publication performance, presenting the seven highest-ranked journals, in order of number of papers published on S-LCA. (As mentioned above, the analysis included 
articles published in journals indexed by the SSCI, SCI-Expanded, AEHCI, and ESCI through December 2018). The International Journal of Life-Cycle Assessment leads this ordering, with a total of 94 papers published through the end of 2018. Journal of Cleaner Production follows, with a total of 24 papers on S-LCA themes. Table 3 also gives the journal's 2018 impact factor.

Table 3. Seven highest-ranked journals, ordered by number of articles on S-LCA.

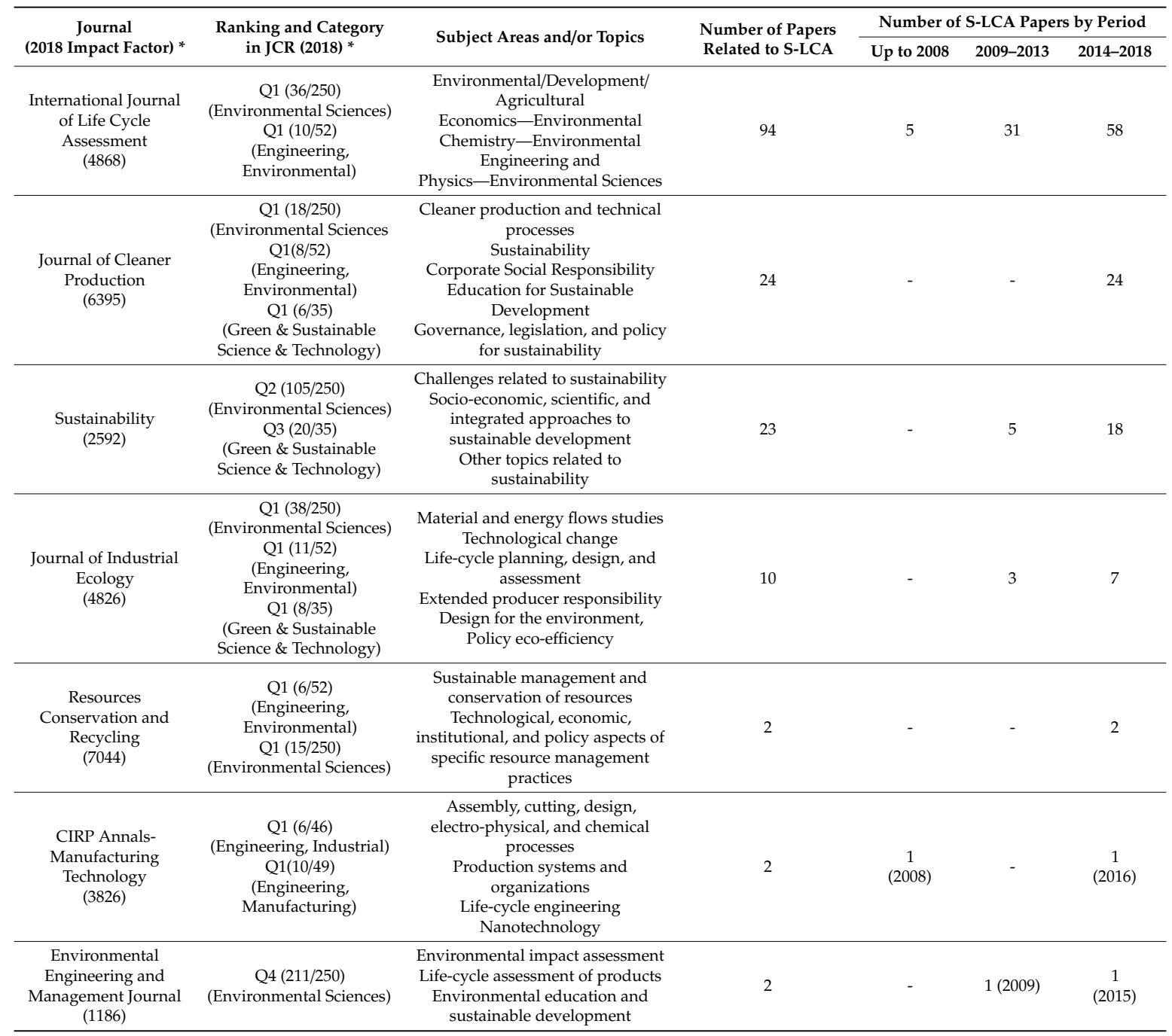

(* Data refer to 2018 published in InCites Journal Citation Reports in 2019).

Most S-LCA articles were published in journals classified in more than one subject category in the Journal Citation Reports (JCR) database, primarily in Environmental Sciences and Engineering (see second column of Table 3). Although S-LCA gains weight as a managerial decision support tool (e.g., for assessing impact of a policy or investment choice, evaluating value chain social risk, verifying ethical compliance), the lack of publication activity on S-LCA in management journals is striking.

Descriptive analysis also enabled the identification of larger contributors in terms of quantity of S-LCA papers published and total citation counts in a specific period. By the end of 2018, a total of 480 authors (mostly in co-authorship) had published at least one article on S-LCA topics. Table 4 lists the top 19 authors who contributed four or more papers on S-LCA, and their most cited paper in WoS (by 21 January 2019). 
Table 4. Top 13 authors per number of contributions and citations (including co-authorships).

\begin{tabular}{|c|c|c|c|}
\hline Author & $\begin{array}{l}\text { Number of S-LCA Articles } \\
\text { Published (Authored or } \\
\text { co-Authored) * }\end{array}$ & $\begin{array}{l}\text { Author's Accumulated } \\
\text { Total Citations in all } \\
\text { S-LCA Documents * }\end{array}$ & $\begin{array}{l}\text { Author's Most Cited Paper } \\
\text { (by Number of Citations) * }\end{array}$ \\
\hline $\begin{array}{l}\text { Finkbeiner, M. } \\
\text { (Matthias) }\end{array}$ & 13 & 397 & $\begin{array}{l}\text { Martínez-Blanco, J., Lehmann, A., Muñoz, P., Antón, A., Traverso, M., } \\
\text { Rieradevall, J., \& Finkbeiner, M. (2014). “Application challenges for the } \\
\text { social Life Cycle Assessment of fertilizers within life cycle sustainability } \\
\text { assessment". Journal of Cleaner Production, 69, 34-48. }\end{array}$ \\
\hline $\begin{array}{l}\text { Traverso, M. } \\
\text { (Marzia) }\end{array}$ & 13 & 383 & $\begin{array}{l}\text { Martínez-Blanco, J., Lehmann, A., Muñoz, P., Antón, A., Traverso, M., } \\
\text { Rieradevall, J., \& Finkbeiner, M. (2014). “Application challenges for the } \\
\text { social Life Cycle Assessment of fertilizers within life cycle sustainability } \\
\text { assessment”. Journal of Cleaner Production, 69, 34-48. }\end{array}$ \\
\hline $\begin{array}{l}\text { Hauschild, MZ } \\
\text { (Michael Z.) }\end{array}$ & 9 & 713 & $\begin{array}{c}\text { Dreyer, L., Hauschild, M., \& Schierbeck, J. (2006). “A Framework for Social } \\
\text { Life Cycle Impact Assessment" (10 pp). The International Journal of Life } \\
\text { Cycle Assessment, 11(2), 88-97. }\end{array}$ \\
\hline $\begin{array}{l}\text { Lehmann, A. } \\
\text { (Annekatrin) }\end{array}$ & 7 & 221 & $\begin{array}{l}\text { Martínez-Blanco, J., Lehmann, A., Muñoz, P., Antón, A., Traverso, M., } \\
\text { Rieradevall, J., \& Finkbeiner, M. (2014). “Application challenges for the } \\
\text { social Life Cycle Assessment of fertilizers within life cycle sustainability } \\
\text { assessment”. Journal of Cleaner Production, 69, 34-48. }\end{array}$ \\
\hline $\begin{array}{l}\text { Benoît, C. } \\
\text { (Benoît-Norris, } \\
\text { Catherine) }\end{array}$ & 6 & 44 & $\begin{array}{l}\text { Benoît, C., Norris, G. A., Valdivia, S., Ciroth, A., Moberg, A., Bos, U., ... } \\
\text { Beck, T. (2010). “The guidelines for social life cycle assessment of products: } \\
\text { just in time!” The International Journal of Life Cycle Assessment, 15(2), } \\
\text { 156-163. }\end{array}$ \\
\hline $\begin{array}{l}\text { Ekener, E. } \\
\text { (Ekener-Petersen, } \\
\text { Elisabeth) }\end{array}$ & 6 & 174 & $\begin{array}{c}\text { Ekener-Petersen, E., \& Finnveden, G. (2013). "Potential hotspots identified } \\
\text { by social LCA-part 1: a case study of a laptop computer". The } \\
\text { International Journal of Life Cycle Assessment, 18(1), 127-143. }\end{array}$ \\
\hline $\begin{array}{l}\text { Dreyer, LC } \\
\text { (Louise } \\
\text { Camilla) }\end{array}$ & 5 & 400 & $\begin{array}{l}\text { Dreyer, L., Hauschild, M., \& Schierbeck, J. (2006). “A Framework for Social } \\
\text { Life Cycle Impact Assessment (10 pp)”. The International Journal of Life } \\
\text { Cycle Assessment, 11(2), 88-97. }\end{array}$ \\
\hline $\begin{array}{l}\text { Ciroth, A } \\
\text { (Andreas) }\end{array}$ & 5 & 272 & $\begin{array}{l}\text { Benoît, C., Norris, G. A., Valdivia, S., Ciroth, A., Moberg, A., Bos, U., ... } \\
\text { Beck, T. (2010). “The guidelines for social life cycle assessment of products: } \\
\text { just in time!” The International Journal of Life Cycle Assessment, 15(2), } \\
\text { 156-163. }\end{array}$ \\
\hline $\begin{array}{l}\text { Ugaya, CML } \\
\text { (Cassia Maria } \\
\quad \text { Lie) }\end{array}$ & 5 & 107 & $\begin{array}{l}\text { Valdivia, S., Ugaya, C. M. L., Hildenbrand, J., Traverso, M., Mazijn, B., \& } \\
\text { Sonnemann, G. (2013). “A UNEP/SETAC approach towards a life cycle } \\
\text { sustainability assessment-our contribution to Rio+20". The International } \\
\text { Journal of Life Cycle Assessment, 18(9), 1673-1685. }\end{array}$ \\
\hline $\begin{array}{l}\text { Petti, L. } \\
\text { (Luigia) }\end{array}$ & 5 & 45 & $\begin{array}{c}\text { Ramirez, P. K. S., Petti, L., Haberland, N. T., \& Ugaya, C. M. L. (2014). } \\
\text { "Subcategory assessment method for social life cycle assessment. Part 1: } \\
\text { methodological framework". The International Journal of Life Cycle } \\
\text { Assessment, 19(8), 1515-1523. }\end{array}$ \\
\hline $\begin{array}{l}\text { Zamagni, A. } \\
\text { (Alessandra) }\end{array}$ & 4 & 465 & $\begin{array}{l}\text { Zamagni, A, Heijungs, R, Guinee, JB, Huppes, G, Masoni, P, Buonamici, R, } \\
\text { Ekvall, T, Rydberg, T. (2011). “Life Cycle Assessment: Past, Present, and } \\
\text { Future”. Environmental Science and Technology, Vol. } 45 \text { (1): 90-96. }\end{array}$ \\
\hline $\begin{array}{l}\text { Klopeffer, W. } \\
\text { (Walter) }\end{array}$ & 4 & 388 & $\begin{array}{l}\text { Kloepffer, W. (2008). "Life cycle sustainability assessment of products". } \\
\text { (with Comments by Helias A. Udo de Haes, p. 95). The International } \\
\text { Journal of Life Cycle Assessment, Vol. 13(2): 89-95. }\end{array}$ \\
\hline $\begin{array}{l}\text { Reveret, JP. } \\
\text { (Jean-Pierre) }\end{array}$ & 4 & 152 & $\begin{array}{l}\text { Reveret, JP, Parent, J, Cucuzzella, C. (2010). "Impact assessment in SLCA: } \\
\text { sorting the sLCIA methods according to their outcomes". International } \\
\text { Journal of Life Cycle Assessment, Vol. } 15 \text { (2): 164-171. }\end{array}$ \\
\hline $\begin{array}{c}\text { Sala, S. } \\
\text { (Serenella) }\end{array}$ & 4 & 100 & $\begin{array}{c}\text { Zamagni, A, Sala, S, Farioli, F. (2013). “Life cycle sustainability assessment } \\
\text { in the context of sustainability science progress (part 2)". International } \\
\text { Journal of Life Cycle Assessment, Vol. 18 (9): 1686-1697. }\end{array}$ \\
\hline $\begin{array}{l}\text { De Luca, AI. } \\
\text { (Anna Irene) }\end{array}$ & 4 & 69 & $\begin{array}{l}\text { Iofrida, N, De Luca, AI, Strano, A, Gulisano, G, Falcone, G (2015). “Social } \\
\text { Life Cycle Assessment and Participatory Approaches: A Methodological } \\
\text { Proposal Applied to Citrus Farming in Southern Italy". Integrated } \\
\text { Environmental Assessment and Management, Vol. } 11 \text { (3): 383-396. }\end{array}$ \\
\hline
\end{tabular}

( ${ }^{*}$ In WOS to date January 21st 2019, when data were downloaded.). 
The contribution of different countries or territories can be analyzed using the authors' addresses [16]. Author affiliation shows that the continent with the most contributions to S-LCA is clearly Europe (300), followed by Asia (111), and North America (69 USA, 22 Canada). Authors from Brazil head South American publications on S-LCA (27 of 29 authors). In Europe, the leading countries by number of authors publishing on S-LCA as of December 2018 are Germany (59), Italy (46), Sweden (28), France (22), Denmark (20), and Spain (20).

\subsection{Salient Themes and Longitudinal Evolution}

Visual mapping enabled characterization of the intellectual structure of the research topic. "The co-word program serves to visualize the resulting configuration of forces by measuring the stability of the intersection of interests that corresponds to the association of words operated by actors" [39] (p. 207). Convergence among words defines the emergence of a topic, showing macro-terms as key forces that associate or dissociate words.

SciMAT analyzed the document to construct a measure of similarity and display a network of themes and their relations, depicting the conceptual and cognitive structure of S-LCA in the literature (see Figure 2). By linking publications' conceptual content, the co-word technique first provided a clear depiction of the nature and strength of linkages between pairs of words and then high frequency of co-occurrence among S-LCA, LCA, and other keywords, such as sustainability, social indicators, framework, methodology, impact assessment, LCC (Life-Cycle Costing), and LCSA (Life-Cycle Sustainability Assessment), among others.

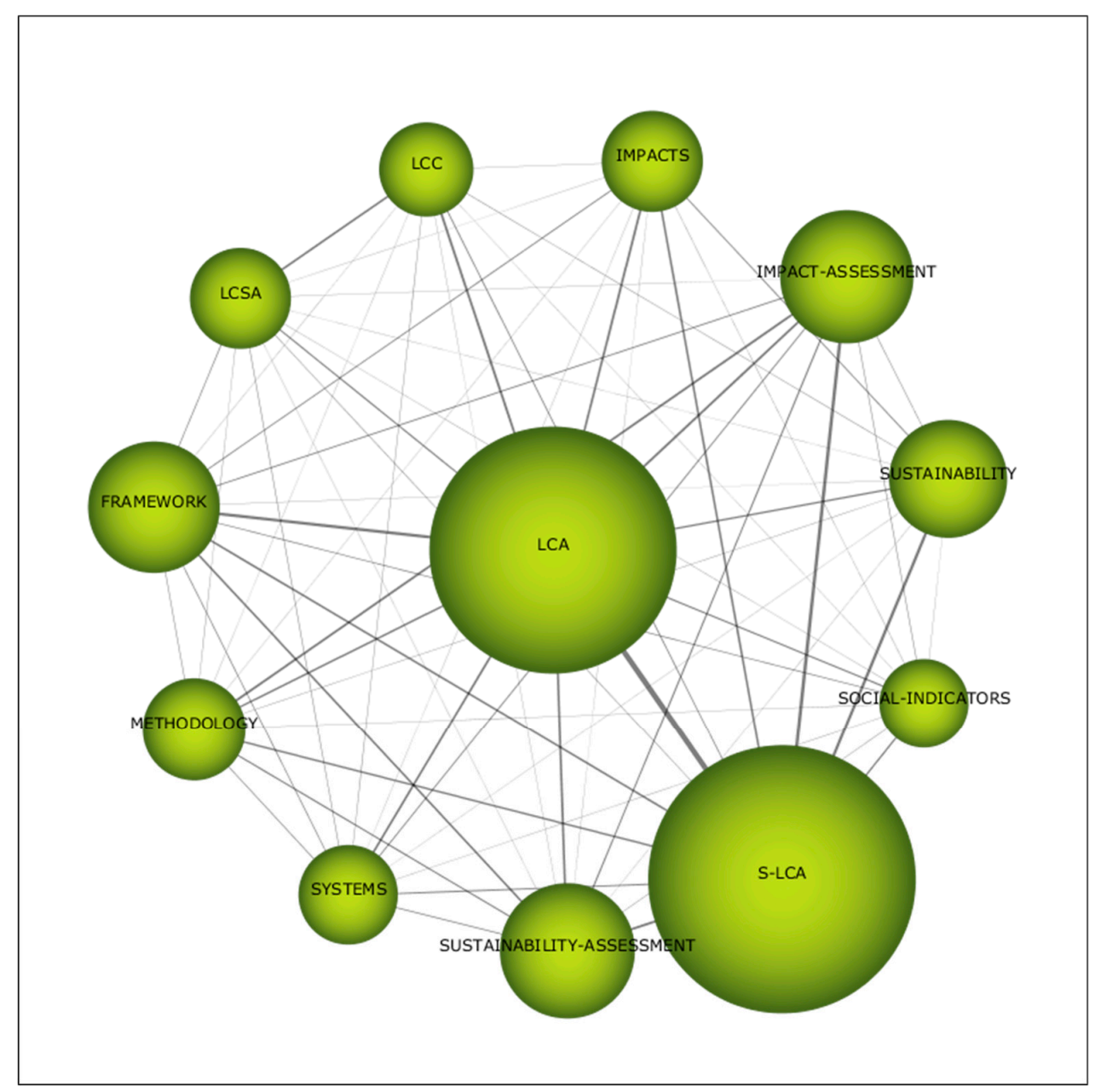

Figure 2. General network of themes in the S-LCA research field. (2003-2018, with no distinction of periods), Strategic map. 
The word framework stands out as an important theme in S-LCA research. The term denotes the need for further theoretical development to better understand the initial epistemological position and underlying social sustainability theory [6]. At epistemological level, many diverse methodological approaches have been proposed for S-LCA studies, and no consensus has emerged on their quality. Focusing on main aims, Jørgensen et al. [29] identified three different uses of S-LCA: consequential S-LCA (focuses on evaluating the social impacts of different alternatives), educational S-LCA (social study that focuses on communication and marketing), and management S-LCA (aims to identify hotspots, i.e., activities more likely to be harmful).

Linkages between LCA and S-LCA are due to strong similarities in their assessment methodologies. Other keywords in Figure 2 indicate issues yet to be resolved or agreed upon, such as impact or social indicator.

SciMAT enables division of the core document set into time periods to conduct longitudinal analysis of the semantic map of the field and investigate its evolution. Such analysis can "capture the development of the field over time," identifying changes in the field's structure [4] (p. 440). In this case, since the 2009 publication of the UNEP/SETAC Guidelines is the key milestone in S-LCA publication activity, co-word analysis was conducted for two periods: Period (1) before publication of the Guidelines (1991-2008), and Period (2) after publication of the Guidelines (2009-2018). Each period produced a strategic map, displayed in Figures 3 and 4. Combining Figures 3 and 4 provides a longitudinal framework of the topic, enabling researchers to visualize the thematic evolution of S-LCA as a research field.

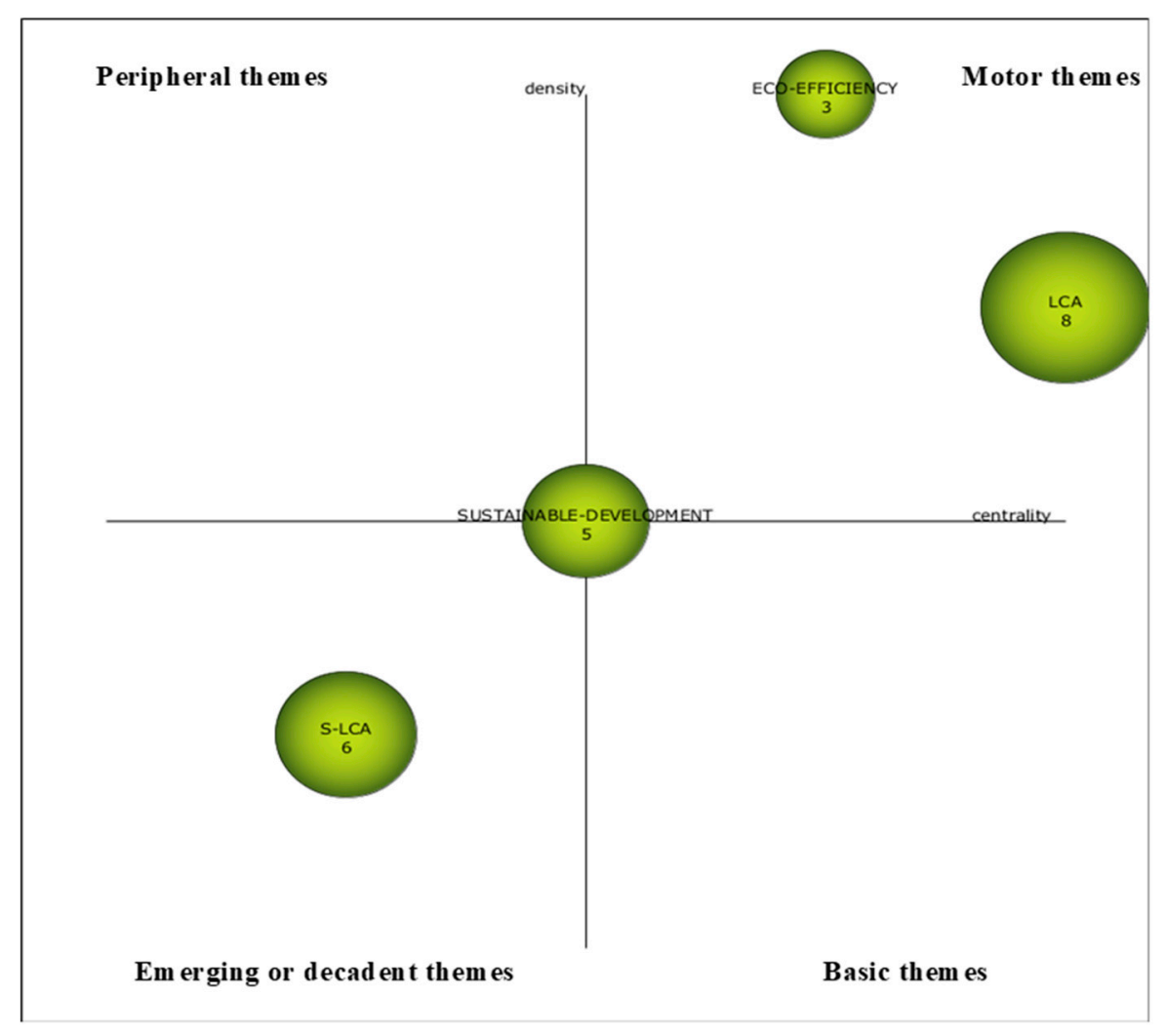

Figure 3. Strategic diagram of S-LCA (based on the number of published documents). Period 1: pre-Guidelines (2003-2008). 3. Strategic diagram of S-LCA (based on the number of published documents). Period 1: pre-Guidelines (2003-2008). 


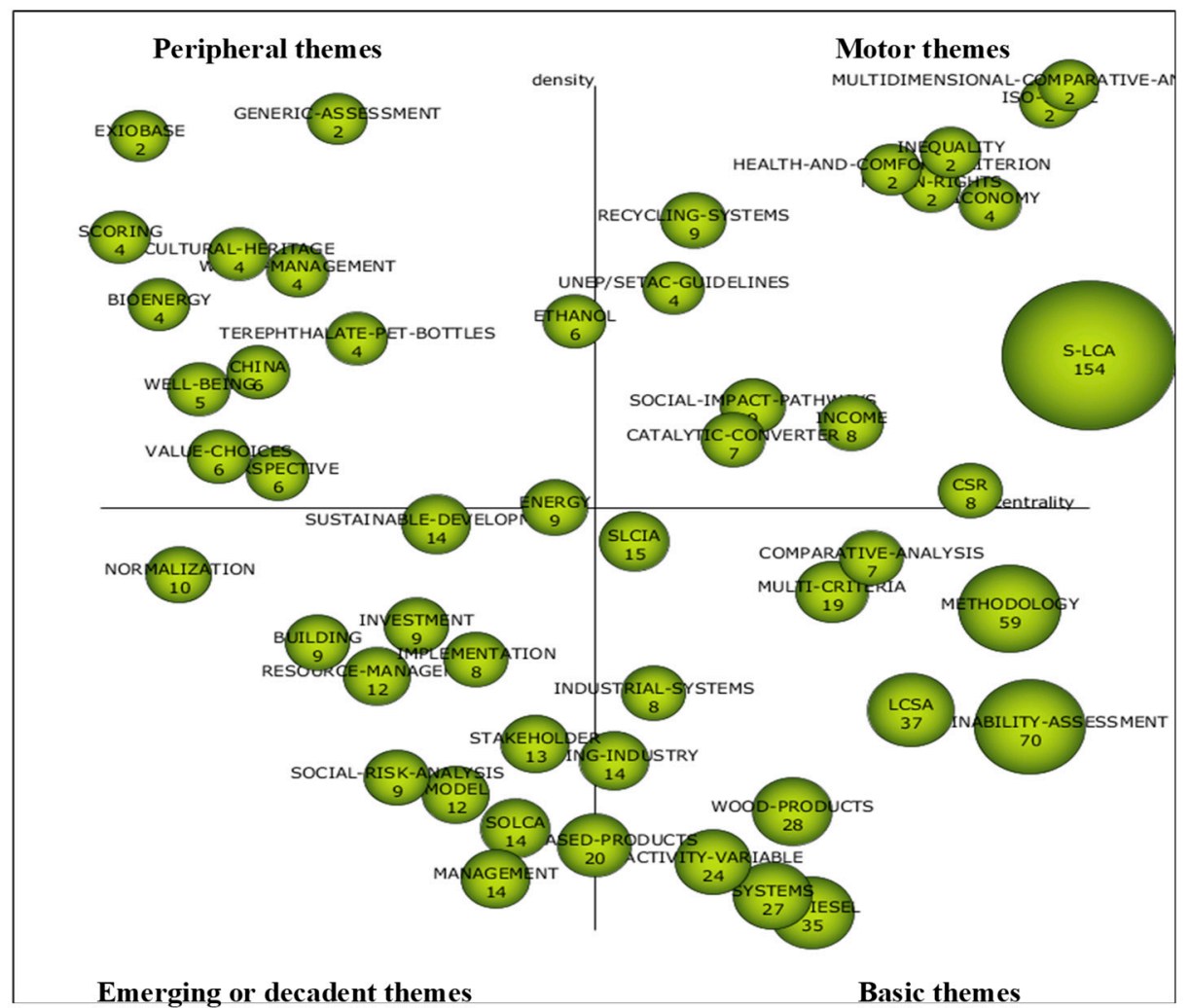

Figure 4. Strategic diagram of S-LCA (based on the number of published documents). Period 2: post-Guidelines (2009-2018).

By establishing minimum keyword frequency (2), calculating the occurrences matrix and equivalence index [43], and applying the simple centers algorithm, a strategic diagram can be created [36,38]. "The strategic diagram is a two-dimensional space built by plotting themes according to their centrality and density rank," based on Callon's centrality (which "measures the degree of interaction of a network with other networks") and density indicators ("measures the internal strength of the network") [5] (p. 150). This diagram enables detection and visualization of conceptual subdomains; and identification of highly developed and/or isolated topics, main research themes, and emerging or disappearing topics, as well as the basic themes present in most studies. The volume of the circles containing each keyword is proportional to the number of documents the term includes. Figures 3 and 4 depict key themes and general thematic areas in S-LCA research by clusters.

The themes in the upper-right quadrant of the strategic quadrant show strong centrality and high density. Both "are both well developed and important for the structuring of a research field"; motor-themes are "related externally to concepts applicable to other themes that are conceptually closely related" [5] (p. 150), as is the case for the topic LCA in the first period and S-LCA in the second. Other themes-such as UNEP/SETAC Guidelines, multidimensional analysis, social impact pathways, human rights, recycling systems, and health—are also classified as motor-themes in the strategy diagram in the second period.

The themes in the upper-left quadrant are of only marginal importance to the field, probably because they are very specialized (as is the case of terephthalate pet bottles, bioenergy, and China in Period 2) or peripheral in character (e.g., exiobase or cultural heritage).

"Themes in the lower-right quadrant are important for a research field but are not developed. So, this quadrant groups transversal and general, basic themes" [5] (p. 151). In the second period, keywords such as methodology, multi-criteria, comparative analysis, wood-products, and SLCIA appear in this quadrant. 
Themes located in the lower-left quadrant are weakly developed and marginal, "mainly representing either emerging or disappearing themes" [5] (p. 150). S-LCA is positioned centrally in this lower-left quadrant during the first period analyzed (2003-2008), clearly indicating its emergence as a pole of interest. In the second period, the topic moves to the upper-right quadrant, signifying its status as a motor theme. In this lower-left quadrant, Social Organizational Life-Cycle Assessment (SO-LCA) appears in the second period as an emerging research topic. SO-LCA is currently gaining research attention as a method to study the impact of the life cycle of the organization itself [44]. SO-LCA goes beyond focus on the product to consider the organization as a whole by compiling and evaluating its social and socioeconomic aspects and the positive and negative impacts of activities within the organization [25]. In fact, the preliminary draft (v2) of the New Guidelines for Social Life-Cycle Assessment provides insights into SO-LCA as an important topic [25].

Other words, such as stakeholder, also appear in this lower-left quadrant in the second period, silhouetted as important research topics awakening further research interest. The UNEP/SETAC Guidelines [3] classify social impacts into five different areas corresponding to the main stakeholder groups mentioned above (workers, consumers, society, value chain actors, and local community) and six different subcategories: working conditions, human rights, health and safety, cultural heritage, governance, and socioeconomic repercussions. The main purpose of S-LCA is to improve the social conditions of all stakeholders involved or affected by the full life cycle of a product or service. We thus expect publications on S-LCA either to refer to stakeholders in general (stakeholders, stakeholder engagement, stakeholder theory) or to investigate topics and variables related to them, as shown by the keywords in the last column in Table 5. Workers' issues are widely investigated (wage, working hours, child labor, health and safety, rates of injury and fatalities, etc.), as are value chain and social issues such as economic development, inequality, and human rights. The findings of Di Cesare et al. [8] suggest that the "worker" is the stakeholder receiving the most attention in S-LCA studies. As the limited number of related keywords in the literature dataset reviewed indicates, consumers and local communities have not received much research attention to date, probably due to difficulty in assessing the use stage, as Jørgensen et al. [12] noted.

Table 5. Main themes in research on stakeholders.

\begin{tabular}{ccc}
\hline Stakeholder & UNEP-SETAC (2009) Subcategories & Related Document Keywords \\
Worker & $\begin{array}{c}\text { Freedom of association and collective bargaining; child labor, } \\
\text { fair salary, working hours, forced labor, equal } \\
\text { opportunity/discrimination, health and safety, social } \\
\text { benefits/social security }\end{array}$ & $\begin{array}{c}\text { worker (4), wage (4), health and safety (6), injuries (2), } \\
\text { working time (2), child labor (2), work (3), labor rights (1) }\end{array}$ \\
\hline Consumer & $\begin{array}{c}\text { Health and safety, feedback mechanism, consumer privacy, } \\
\text { transparency, end-of-life responsibility }\end{array}$ & $\begin{array}{c}\text { consumption (4), consumers (1), end-of-life product (1), } \\
\text { human health (2) }\end{array}$ \\
\hline Local community & $\begin{array}{c}\text { Access to material resources, access to immaterial resources, } \\
\text { delocalization and migration; cultural heritage, safe and } \\
\text { healthy living conditions, respect for indigenous rights, } \\
\text { community engagement, local employment, secure living } \\
\text { conditions }\end{array}$ & $\begin{array}{c}\text { cultural heritage (1), community (1), local communities (1), } \\
\text { employment (2) unemployment (1) }\end{array}$ \\
\hline Society & $\begin{array}{c}\text { Public commitment to sustainability issues, contribution to } \\
\text { economic development, prevention and mitigation of armed } \\
\text { conflicts, technology development, corruption }\end{array}$ & $\begin{array}{c}\text { economic development (4), sustainable society index (1), crime } \\
\text { (1), sustainable child development index (1), justice (2), } \\
\text { inequality (2) income inequality (3), human rights (3), informal } \\
\text { sector (2), poverty (4), school attendance (1), mortality (2) }\end{array}$ \\
\hline $\begin{array}{c}\text { Value chain actors } \\
\text { (not including consumers) }\end{array}$ & $\begin{array}{c}\text { Fair competition, promotion of social responsibility, supplier } \\
\text { relationships, respect for intellectual property rights }\end{array}$ & $\begin{array}{c}\text { supply chain (10), supply-chain management (5), } \\
\text { humanitarian supply chains (1), logistics (1), competition, } \\
\text { social responsibility (7) }\end{array}$ \\
\hline
\end{tabular}

(number of documents in parentheses).

In sum, the morphology of word networks changed across the different periods studied, while some words changed location in the strategic quadrant and new words appear. During the first period (before publication of the UNEP/SETAC Guidelines), LCA was the motor theme in most studies and S-LCA an emerging topic (see Figure 3). Research gradually shifted focus to testing the feasibility of the UNEP/SETAC $(2009,2013)[3,22]$ methodological proposals in different sectors, processes, and companies; many publications highlighted the need for improvement and completion of this nascent methodology [23]. New attention then focused on detecting areas influenced by the 
company's action and effects, as experienced directly or indirectly by the stakeholders affected (due to the way an activity is organized or implemented in the product/service life cycle or to the intrinsic characteristics of product utility).

Figure 5 depicts the evolution map of S-LCA as a topic based on the keywords detected in the literature before and after publication of the Guidelines. During the first period (2003-2008), very little was written about S-LCA; only 46 keywords were identified. The stability index represents the behavior and stability of the field over time, detecting number of keywords shared by two periods, as well as number of new keywords introduced in the second period; 32 of the 46 keywords related to S-LCA detected in the first period (1991-2008) received further study after publication of the UNEP-SETAC Guidelines (during the second period, 2009-2018). The most interesting point is the introduction of more than 500 new keywords in the second period. Figure 5 shows over 542 new keywords in the second period (with only 14 from the first period no longer studied); during this second period, words such as methodology, model, SOLCA, stakeholders, normalization, social risk analysis, and multicriteria were introduced. This change demonstrates a huge increase in research interest in new topics in the field of S-LCA and remarkable growth of scholarly activity on S-LCA after publication of the UNEP/SETAC Guidelines in 2009.

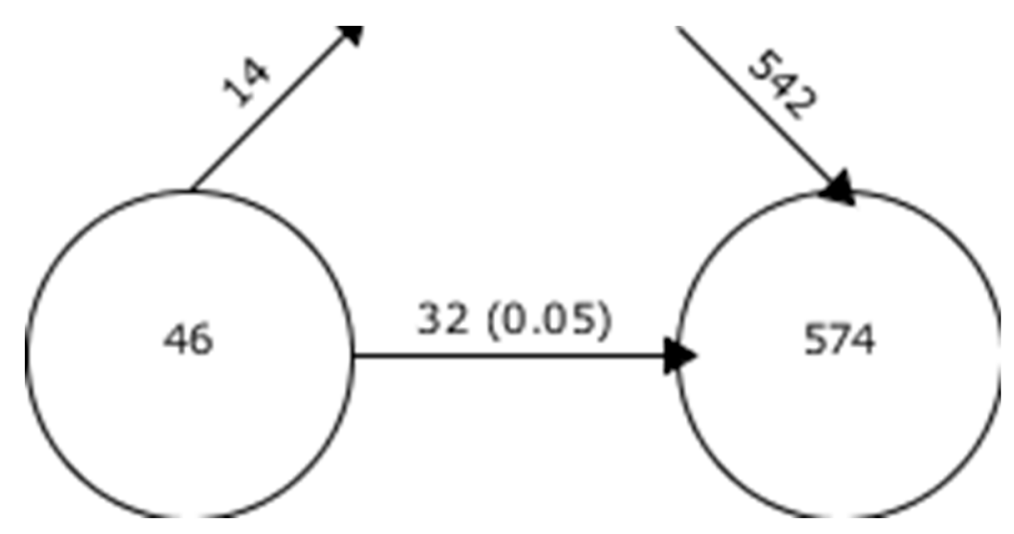

Figure 5. Stability of keywords across periods (2003-2008/2009-2018). (Incoming and outgoing keywords between successive subperiods; inclusion index in brackets: 0.05 ).

Keyword output of the dataset also shows how S-LCA methodology has been applied to different sectors in recent years. The sectors include primarily agriculture (tomatoes, sugarcane, raspberries, citrus growing, bananas, etc.) [45-47], food products (honey, eggs, milk) [48,49], forestry, chemical industry (chemicals, phosphorus fertilizers, terephthalate pet bottles, polyethylene) [50,51], bioenergy (bioenergy, biofuel, biomass, bioethanol, palm oil) [26,52,53], building and construction (building materials, concrete, buildings, retrofitting, steel industry, etc.) [54-56], transport and automobiles (electric vehicles, airbag, sustainable transport, etc.) [57-59], and waste management (food waste, municipal solid waste, solid waste, etc.) [60,61]. Growing concern that farm and industrial activities significantly impact many actors is probably the main reason that studies proliferate in these fields [24]. Other sectors with some S-LCA studies include electronics (mobile phone, lithium ion batteries, laptop, software), wood industry, textiles (clothing, fashion, textiles, etc.), jewelry, mining, water management (drinking water, wastewater treatment), recycling systems, and toy manufacturing.

Countries where case studies of S-LCA have been conducted include Hong-Kong, Australia, Canada, the United States, China, Taiwan, New Zealand, the Netherlands, Brazil, India, Thailand, Malaysia, Mauritius, Indonesia, Cameroon, Algeria, Pakistan, and Ecuador. Interest in using S-LCA methods as a decision support tool is increasing in developing projects in low-income and developing countries [27]. 


\section{Discussion}

\subsection{Overview of S-LCA Research}

This analysis of key bibliometric indicators across fifteen years of S-LCA research activity (2003-2018) shows significant growth in the number of papers in the last decade. This surge in S-LCA research is likely due to the 2009 publication of UNEP/SETAC's Guidelines for Social Life Cycle Assessment of Products and 2013 publication of the Methodological Sheets for Subcategories in Social Life Cycle Assessment, two key documents that guide stakeholders in socioeconomic impact assessment of product life cycles. Before publication of these documents, very few S-LCA case studies had been performed [29]. After 2009, case studies analyzing S-LCA proliferated, revealing researchers' willingness to apply the UNEP/SETAC Guidelines. Our analysis confirms S-LCA as an emergent area of research, with $66 \%$ of all articles (125/188) on the topic during the period studied published in the last four years. Data suggest that research in this field will continue to grow in years to come, as research is in the early stages. By 2018, 480 authors had contributed to S-LCA research. The most productive region was Europe, led by Germany and Italy in S-LCA publications. This finding can be explained by the European Commission's strong commitment to sustainability and to funding and fostering LCA and related research projects (e.g., http://sosmarteu.eu/, https://www.forture-life.eu). The United Nations' Life Cycle Initiative (https://www.lifecycleinitiative.org/) has also been crucial in supporting and promoting S-LCA initiatives and associated research projects.

\subsection{Areas of Application of S-LCA}

The social life cycle has been assessed in sectors such as bioenergy, agriculture, building construction, waste management, and water management, among others. "The works in the literature have been predominantly focused on product analysis" [62] (p. 608), with little application to service delivery in research. Very few papers apply S-LCA to product-service systems, as Sousa-Zomer and colleagues do for the water sector [62]. Although "touristic activities [are] well suited for the elaboration of data related to social sustainability" [23] (p.5) and despite the huge impact of waste generation by activities such as hospitality [63], only one study applies S-LCA as a management in tool in a service sector such as tourism. Jørgensen et al. [64] propose the value of analyzing not only the direct effect of S-LCA but also more indirect impacts, looking beyond impacts created by process or product use to the impact of non-production or non-use. Indirect impact could be conducted by analyzing potential impact on the lives of key stakeholders had the product or service not been produced (in terms, for example, of workers' socio-economic status or unemployment rates) or used.

\subsection{S-LCA as a Strategic-Thinking Solution}

All in all, S-LCA provides powerful support for managerial decision-making. Moreover, sustainability issues are important factors for the organization's competitiveness in image and credibility on the market [23]. Paradoxically, despite growing urgency to integrate sustainability into managerial decision-making due to both the importance of sustainability management in companies and the gains in S-LCA as a managerial decision support tool, there is striking lack of publication activity on S-LCA in Management journals. International Journal of Life Cycle Assessment, Journal of Cleaner Production, and Sustainability lead in number of papers published on S-LCA during the period reviewed. None of the top journals in the field is ranked in the Management subcategory in JCR, although some are ranked in other categories, such as Engineering and Environmental Sciences. This pattern is similar to that obtained by Onat et al. [27] for different disciplines' contributions to LCSA studies in general: highest number of LCSA studies (40\%) in Environmental Science and 18\% in Engineering, while contributions from Economics and Business were very low (3\% and 5\%, respectively). This lack of research and focus on S-LCA in Management represents a clear gap to be filled in the future. Various managerial disciplines can surely contribute to developing crucial aspects of S-LCA. Drawing on the Resource-Based View [65], for example, strategic management 
experts can advance the field by discovering whether companies conducting S-LCA as a firm capability obtain a sustainable competitive advantage over time compared to their competitors. It would also be interesting to increase understanding of how to develop more sustainable business models [66] and create stakeholder sustainability engagement [67]. From a Human Resources Management perspective, it could be pivotal to develop mechanisms that foster employee voice, as the worker is one of the stakeholders most impacted in S-LCA [68]. This focus could integrate the employee's perspective to promote more socially sustainable practices. Marketing experts can help to disseminate the importance of purchasing products and services from socially responsible companies that monitor and reduce their negative social impacts. Such efforts could benefit greatly from effective communication plans [69]. Through on-product communication (e.g., social sustainability labelling), off-product communication (in-person events, meet-ups), or online campaigns (social media, websites), companies could show the market their higher level of social sustainability commitment. Management scholars could also develop managerial tools, such as decision support systems (DSS) or enterprise resource planning systems (ERPs) to measure and compare the environmental, economic, and social sustainability of different organizational actions in order to make more informed decisions.

\subsection{Methodological and Theoretical Concerns Related to S-LCA}

Since the S-LCA methodology is intended to complement LCA and LCC in developing a holistic sustainability assessment method such as LCSA [7,28], a major methodological challenge is undoubtedly implementation of a combination of LCA, LCC, and S-LCA [31]. Analyzing the most important words (keywords) in the documents enables us to study the conceptual structure of the S-LCA research field and hot topics within it. Through analysis of the co-occurrence of terms, co-word technique visualizes the state-of-art research in this field, illustrating the relations between various themes and identifying emerging areas of research [3]. In line with prior research [9], our science mapping analysis identifies a rapid succession of different topics related to S-LCA in the last few years, and a recent and highly fragmented field of study currently.

In S-LCA, there are two main types of impact assessment (LCIA). The difference between type I and type II lies in the characterization model (the evaluation method) [70]. Type I methods use performance reference points (PRPs) to assess and report inventory data, whereas type II includes cause-effect chains or impact pathways in the analysis, using characterization factors based on measurements of causal links in impact pathways- [70,71].

Type I "provides a qualitative assessment of the social performance of a product system's activity" [72] (p. 2008). Important issues in type I SLCA methods involve the characterization step (what the inventory data is assessed against) and the weighting method. Characterization is the step during which the data is analyzed to assess its meaning in terms of its potential to cause social impacts. In this step, "an implicit or explicit value judgment is made on the collected data" [70] (p. 433). The six most frequently used characterization methods in the literature are based: on norms and best practices, on norms and socio-economic context, on stakeholders' judgements of companies' compliance with norms, on researchers'/experts' judgement of companies' activities, on a distribution of performances, and on comparison of alternatives. "At the weighting step, the characterization results are given a different relative weight" [72] (p. 433), "based on the relative importance attributed to different subcategories (e.g., salary and working hours) inside an impact category (e.g., working conditions) and a stakeholder category (e.g., worker), or an equal weighting can be attributed to all results. It can also be based on the relative importance of the unit processes or the life cycle steps in the studied product system". Up to five types of weighting methods have been identified based: on implicit equal weighting, on the worst performance for a given subcategory, on stakeholders'/experts'/users' judgement of importance of issues, on UN conventions, and on activity variable.

Regarding Type II, Sureau et al.'s review [71] provides the most recent classification of existing type II approaches. Analysis of these approaches reveals three main paths to include impact pathways in S-LCA depending on the authors' intentions: “(1) some studies identify and propose variables 
composing impact pathways, or frameworks gathering several pathways; (2) other studies investigate or test known pathways empirically, and until now seek mainly to link income data with health impacts at a macro scale, and (3) a last batch applies known and already quantified characterization models or factors from other research works in case studies" [71] (p. 382).

Nevertheless, lack of consensus on social indicators is still one of the main challenges of S-LCA, as Kühnen and Hahn [73] stress after conducting a Delphi study of experts. Further, unresolved definitional challenges include complexity of social and cultural issues, as well as limited regulation; other methodological challenges associated with S-LCA are limited availability of data, complexity of supply chains, and lack of technical know-how in social assessment methods.

In sum, S-LCA still lacks a standard homogeneous code of practice [9]- this can explain the numerous attempts of the scholar community to develop methodological solutions to conduct assessment. S-LCA is thus a methodology under continuous development that can be applied at micro(product and/or company), meso- (economic sector or region), and macro- (country, state) levels [8,74]. This flexibility may explain why so many contributions present different approaches to S-LCA in different sectors. Further, since S-LCA methods are still being discussed and developed, it is not surprising that Methodology is a transversal, general, and basic topic in S-LCA studies, remaining an important keyword in the S-LCA domain. Significant efforts have been made to pursue systematization and homogenization in applying S-LCA, as well as the UNEP/SETAC Guidelines [3].

Jørgensen et al. [12] identify other S-LCA approaches in the literature (e.g., cost-benefit analysis, quality adjusted life years (QALY) [75], and social sustainability in supply-chains [76]. Nevertheless, no standard method has been adopted unanimously, and the different proposals still face a number of methodological challenges. In fact, studies frequently employ different inputs, procedures, and methods to assess S-LCA based on the researcher's priorities, resulting in a broad variety of approaches, particularly in choice and formulation of indicators. Furthermore, divergence in S-LCA approaches seems to be conditioned by the study's focus: impacts created in proximity to production processes vs. more remote societal consequences [12]. This finding confirms "the difficulty of realizing a common strategic vision on future developments," [9] (p. 403). The absence of a clear methodology to quantify social impact could in some cases affect evaluation of impacts through evaluator subjectivity. The UNEP/SETAC impact analysis list seems to be commonly used and consensually accepted, but additional efforts are necessary to enhance comparability among studies following the guidelines. Some aspects, such as potential impacts on human well-being, are still under debate, and some subcategories are still criticized [7].

Another salient keyword in this study of S-LCA is framework. In S-LCA publications, it is frequently difficult to determine the research paradigm grounding the study. In a critical review of 133 papers on S-LCA, Iofrida, et al. [6] capture the epistemological viewpoint of their authors and identify most of them $(73 \%)$ following an interpretivist paradigm. These authors find that $24 \%$ of the papers ascribe to the post-positivist paradigm, while $3 \%$ of the studies reviewed present characteristics of both epistemological views. Whereas positivist paradigms dominate research orientation in the natural sciences, social science phenomena are more difficult to capture from a single standpoint. It may be precisely the greater epistemological eclecticism in social sciences that explains the diverse epistemological positions that have emerged in S-LCA. Up to 14 different methodological frameworks were identified in this field. Further, applying a specific framework involves following a predefined set of criteria that influence significantly the social issues covered in each study [7]. As Macombe et al. [74] observe, it is important first to differentiate between an effect (a social phenomenon caused by a change that could have impacts) and an impact (consequences of a change felt by people in life).

\subsection{S-LCA to Improve Stakeholder Engagement}

The ultimate goal of S-LCA is to promote improvements in stakeholder-related social conditions. In line with prior research [7], the results of this paper show uneven coverage of stakeholders, life-cycle stages, and topics in the S-LCA literature. For example, stage agents and relationships between value 
chain actors have received less attention than has stakeholder intervention at the production stage. This focus can be explained by the results of Wang et al. [77], which indicate that not all stakeholders are equally relevant and that a weighting system is advisable (the authors propose an analytic hierarchy process combined with consistent fuzzy preference relations). Worker issues are the topics most researched in the S-LCA literature. Within this category, "preventing forced work practices, protecting children from having to work, and providing minimum and fair wages for workers are the three most important indicators for assessing social impact" [77] (p. 1514). Some cases would benefit from more detailed specification of the list of stakeholders, for example, specifying different types of workers (e.g., women or migrant workers) within the worker category, as the preliminary draft of the New Guidelines [25] recommends. Shemfe et al. [31] (p. 1) call for further research on stakeholder engagement in general "to fully grasp the potential social risks."

Zimdars et al. [78] note the exclusion of major stakeholder groups from product-oriented S-LCA studies when working hours are the only metric. Despite the UNEP-SETAC categorization of five main stakeholder groups (namely, workers, consumers, local communities, society, and other value chain actors), the literature continues to express concern about how to extend the range of stakeholders affected by a product's life cycle. In fact, "consumers and value chain actors and society are often overlooked as stakeholder categories, while workers and local communities appear to be frequently included in studies" [25] (p. 32). Along these lines, the steering committee members and working group contributors to the new version of the S-LCA Guidelines are working to introduce new stakeholders (such as children or future generations, smallholders or small-scale entrepreneurs, and informal sector workers) into the analysis. Moreover, the preliminary draft version of the new guidelines recommends that practitioners "develop new stakeholder categories or subdivide existing ones, if relevant to the studied product or service" to ensure that studies take into account more vulnerable stakeholders without a voice in power relations [25] (p. 32). Other recent studies, such as [79], call for inclusion of animal welfare as a distinct social impact category in the future S-LCA official framework. These authors have developed a methodology to recognize animal issues within any stakeholder group (e.g., overall animal welfare impact).

The new version of the UNEP/SETAC Guidelines, to be published soon, contains more comprehensive and analytical clues to enlighten S-LCA practitioner decision-making and better guide S-LCA researchers. In addition, recent publications, such as the UNEP [69] report Shout it Out: Communicating Products' Social Impacts and the Handbook for Product Impact Assessment [80] published by the Roundtable of Social Product Metrics, present novel methods with specific sets of indicators to assess social impacts at product and company level. All of these recent contributions will surely help to refine the technique in the coming years.

\section{Conclusions}

The findings of this study reveal S-LCA to be an emerging topic closely associated with LCA (E-LCA). The field's publication pattern has been growing over the past decade (led by European authors from Germany and Italy), due primarily to both Environmental Science and Engineering, and published primarily in the International Journal of Life Cycle Assessment. S-LCA papers are frequently presented as case studies of the life cycle of agricultural, bioenergy, and chemical products (among others), conducted mostly in non-European countries. Although many theoretical and methodological questions in S-LCA still require consensus and resolution, great effort has already been made to homogenize assessment steps, indicators, and database development.

\section{Implications}

This paper improves understanding of the published research on S-LCA in several ways. First, it provides a descriptive analysis of the top authors, works, and journals in S-LCA, and tracks evolution of the concept. Its findings provide useful input for selection of subtopics and sectors of implementation in future research on S-LCA. Our results also help researchers, managers, educators, 
and students interested in S-LCA to decide on what journals to read and/or subscribe and which author's work(s) to search out. For scholars conducting S-LCA research, for example, this study serves as a starting point for a literature review of research on any of the subject areas identified by the keyword indicators. Second, our study provides a visual summary of the main research topics associated with this area of S-LCA and identifies the most significant. Analyzing publication patterns can lead to proposal of future research avenues in the main or emerging areas of interest detected in S-LCA. Third, our explanation of the methodological steps followed can guide scholars in scientific mapping analysis. Finally, as Zupic and Čater [4] (p. 436) stress, "bibliometrics can help journal editors to evaluate past publications, design new policies, and make editorial decisions."

\section{Bibliometric Analysis: Limitations and Future Research}

The quality of the results of the co-word analysis depends on scope of the database, precision of the keywords authors use in their abstracts, keyword selection (whether these actually capture all significant aspects of the text), and sophistication of the software used to conduct the analyses. The present study aims to reveal the structure and dynamics of S-LCA as a research field. Although science mapping has proven to be a very useful tool for obtaining a systematic, transparent, reproducible review process that enables researchers to identify the most influential works [4], this study is not free of limitations.

One limitation of the scope of this study is that it includes only journal articles in WoS in the analysis. Since WoS includes only journals with an official impact factor, it takes time for newer journals to be included in this database, and some important and recent publications may have been missed. For this reason, further research should include other databases, such as Scopus or Google Scholar, to provide more complete description of the intellectual structure of the field [38].

Although SciMAT software is a powerful bibliometric tool, this open-source program is still unable to complete some analyses (i.e., authors affiliations, leading countries in some research fields). It would also be interesting to map institutional collaboration (works resulting from national or international collaboration among different institutions) to enrich performance analysis. To this end, the analyses provided by SciMAT could be complemented by other user-friendly utilities, such as VOSviewer.

This research focuses on co-word analysis only to illustrate the main knowledge areas and related topics in S-LCA research. Complementary bibliometric techniques such as author bibliographic coupling or journal bibliographic coupling would enable deeper analysis by identifying authors and journals that cite the same references. Further analyses (e.g., Lotka's law, Bradford's law, and/or Price's law) could be calculated with different software to determine whether the subject follows classical bibliometric laws [81].

Author Contributions: Conceptualization I.H.-V.; research design D.S.-B. and I.H.-V.; resources A.M.F.; supervision, F.E.G.-M.; formal analysis, I.H.-V.; data validation A.M.F.; methodology, I.H.-V.; project administration, D.S.-B.; writing — original draft preparation, I.H.-V.; writing — review and editing, I.H.-V. and F.E.G.-M. All authors have read and agreed to the published version of the manuscript.

Funding: This research was co-funded by the European Union's LIFE Program, grant number: LIFE16 ENV/IT/000307 (LIFE Force of the Future).

Acknowledgments: The authors would like to acknowledge the editor and the two anonymous reviewers for their helpful suggestions to improve the paper.

Conflicts of Interest: The authors declare no conflict of interests.

\section{References}

1. Norris, C.; Norris, G.; Aulisio, D. Efficient Assessment of Social Hotspots in the Supply Chains of 100 Product Categories Using the Social Hotspots Database. Sustainability 2014, 6, 6973-6984. [CrossRef]

2. Fauzi, R.T.; Lavoie, P.; Sorelli, L.; Heidari, M.D.; Amor, B. Exploring the Current Challenges and Opportunities of Life Cycle Sustainability Assessment. Sustainability 2019, 11, 636. [CrossRef] 
3. UNEP/SETAC. Guidelines for Social Life Cycle Assessment of Products. Available online: http://www.unep. $\mathrm{fr} /$ shared/publications/pdf/dtix1164xpa-guidelines_slca.pdf (accessed on 31 July 2020).

4. Zupic, I.; Čater, T. Bibliometric Methods in Management and Organization. Organ. Res. Methods 2015, 18, 429-472. [CrossRef]

5. Cobo, M.J.; López-Herrera, A.G.; Herrera-Viedma, E.; Herrera, F. Science mapping software tools: Review, analysis, and cooperative study among tools. J. Am. Soc. Inf. Sci. Technol. 2011, 62, 1382-1402. [CrossRef]

6. Iofrida, N.; De Luca, A.I.; Strano, A.; Gulisano, G. Can social research paradigms justify the diversity of approaches to social life cycle assessment? Int. J. Life Cycle Assess. 2018, 23, 464-480. [CrossRef]

7. Sureau, S.; Mazijn, B.; Garrido, S.R.; Achten, W.M.J. Social life-cycle assessment frameworks: A review of criteria and indicators proposed to assess social and socioeconomic impacts. Int. J. Life Cycle Assess. 2018, 23, 904-920. [CrossRef]

8. Di Cesare, S.; Silveri, F.; Sala, S.; Petti, L. Positive impacts in social life cycle assessment: State of the art and the way forward. Int. J. Life Cycle Assess. 2018, 23, 406-421. [CrossRef]

9. Arcese, G.; Lucchetti, M.C.; Massa, I.; Valente, C. State of the art in S-LCA: Integrating literature review and automatic text analysis. Int. J. Life Cycle Assess. 2018, 23, 394-405. [CrossRef]

10. Bonilla-Alicea, R.J.; Fu, K. Systematic Map of the Social Impact Assessment Field. Sustainability 2019, 11, 4106. [CrossRef]

11. Jørgensen, A. Social LCA-A way ahead? Int. J. Life Cycle Assess. 2013, 18, 296-299. [CrossRef]

12. Jørgensen, A.; Le Bocq, A.; Nazarkina, L.; Hauschild, M. Methodologies for social life cycle assessment. Int. J. Life Cycle Assess. 2008, 13, 96-103. [CrossRef]

13. Mattioda, R.A.; Mazzi, A.; Canciglieri, O.; Scipioni, A. Determining the principal references of the social life cycle assessment of products. Int. J. Life Cycle Assess. 2015, 20, 1155-1165. [CrossRef]

14. Petti, L.; Serreli, M.; Di Cesare, S. Systematic literature review in social life cycle assessment. Int. J. Life Cycle Assess. 2018, 23, 422-431. [CrossRef]

15. Chen, H.; Yang, Y.; Yang, Y.; Jiang, W.; Zhou, J. A bibliometric investigation of life cycle assessment research in the web of science databases. Int. J. Life Cycle Assess. 2014, 19, 1674-1685. [CrossRef]

16. Hou, Q.; Mao, G.; Zhao, L.; Du, H.; Zuo, J. Mapping the scientific research on life cycle assessment: A bibliometric analysis. Int. J. Life Cycle Assess. 2015, 20, 541-555. [CrossRef]

17. Ramos Huarachi, D.A.; Piekarski, C.M.; Puglieri, F.N.; de Francisco, A.C. Past and future of Social Life Cycle Assessment: Historical evolution and research trends. J. Clean. Prod. 2020, 264, 121506. [CrossRef]

18. Guidelines for Life-Cycle Assessment: A 'Code of Practice'. Available online: https://pubmed.ncbi.nlm.nih. gov/24234150/ (accessed on 31 July 2020).

19. O'Brien, M.; Doig, A.; Clift, R. Social and environmental life cycle assessment (SELCA): Approach and methodological development. Int. J. Life Cycle Assess. 1996, 1, 231-237. [CrossRef]

20. Dreyer, L.; Hauschild, M.; Schierbeck, J. A Framework for Social Life Cycle Impact Assessment (10 pp). Int. J. Life Cycle Assess. 2006, 11, 88-97. [CrossRef]

21. Gauthier, C. Measuring Corporate Social and Environmental Performance: The Extended Life-Cycle Assessment. J. Bus. Ethics 2005, 59, 199-206. [CrossRef]

22. UNEP/SETAC (United Nations Environment Programme and Society for Environmental Toxicology and Chemistry). The Methodological Sheets for Sub-Categories in Social Life Cycle Assessment (S-LCA). 2013. Available online: https://www.lifecycleinitiative.org/wp-content/uploads/2013/11/S-LCA_methodological_ sheets_11.11.13.pdf (accessed on 15 January 2019).

23. Arcese, G.; Lucchetti, M.C.; Merli, R. Social life cycle assessment as a management tool: Methodology for application in tourism. Sustainability 2013, 5, 3275-3287. [CrossRef]

24. Iofrida, N.; Strano, A.; Gulisano, G.; De Luca, A.I. Why social life cycle assessment is struggling in development? Int. J. Life Cycle Assess. 2018, 23, 201-203. [CrossRef]

25. UNEP. Guidelines for Social Life Cycle Assessment vs. 2 Draft; 2019; unpublished document.

26. Manik, Y.; Leahy, J.; Halog, A. Social life cycle assessment of palm oil biodiesel: A case study in Jambi Province of Indonesia. Int. J. Life Cycle Assess. 2013, 18, 1386-1392. [CrossRef]

27. Lehmann, A.; Zschieschang, E.; Traverso, M.; Finkbeiner, M.; Schebek, L. Social aspects for sustainability assessment of technologies—challenges for social life cycle assessment (SLCA). Int. J. Life Cycle Assess. 2013, 18, 1581-1592. [CrossRef] 
28. Onat, N.; Kucukvar, M.; Halog, A.; Cloutier, S. Systems Thinking for Life Cycle Sustainability Assessment: A Review of Recent Developments, Applications, and Future Perspectives. Sustainability 2017, 9, 706. [CrossRef]

29. Jørgensen, A.; Dreyer, L.C.; Wangel, A. Addressing the effect of social life cycle assessments. Int. J. Life Cycle Assess. 2012, 17, 828-839. [CrossRef]

30. Benoît-Norris, C.; Cavan, D.A.; Norris, G. Identifying social impacts in product supply chains: Overview and application of the social hotspot database. Sustainability 2012, 4, 1946-1965. [CrossRef]

31. Shemfe, M.; Gadkari, S.; Sadhukhan, J. Social Hotspot Analysis and Trade Policy Implications of the Use of Bioelectrochemical Systems for Resource Recovery from Wastewater. Sustainability 2018, 10, 3193. [CrossRef]

32. Tsalidis, G.A.; Gallart, J.J.E.; Corberá, J.B.; Blanco, F.C.; Harris, S.; Korevaar, G. Social life cycle assessment of brine treatment and recovery technology: A social hotspot and site-specific evaluation. Sustain. Prod. Consum. 2020, 22, 77-87. [CrossRef]

33. Du, C.; Ugaya, C.; Freire, F.; Dias, L.C.; Clift, R. Enriching the results of screening social life cycle assessment using content analysis: A case study of sugarcane in Brazil. Int. J. Life Cycle Assess. 2018, 1-13. [CrossRef]

34. Ciroth, A.; Eisfeldt, F. PSILCA-A Product Social Impact Life Cycle Assessment Database, Database version 1.0; GreenDelta GmbH: Berlin, Germany, 2016.

35. Barrios, M.; Borrego, A.; Vilaginés, A.; Ollé, C.; Somoza, M. A bibliometric study of psychological research on tourism. Scientometrics 2008, 77, 453-467. [CrossRef]

36. Cobo, M.J.; López-Herrera, A.G.; Herrera-Viedma, E.; Herrera, F. SciMAT: A new science mapping analysis software tool. J. Am. Soc. Inf. Sci. Technol. 2012, 63, 1609-1630. [CrossRef]

37. Cobo, M.J.; López-Herrera, A.G.; Herrera-Viedma, E.; Herrera, F. An approach for detecting, quantifying, and visualizing the evolution of a research field: A practical application to the Fuzzy Sets Theory field. J. Informetr. 2011, 5, 146-166. [CrossRef]

38. Corrales-Garay, D.; Ortiz-de-Urbina-Criado, M.; Mora-Valentín, E.-M. Knowledge areas, themes and future research on open data: A co-word analysis. Gov. Inf. Q. 2018. [CrossRef]

39. Callon, M.; Courtial, J.-P.; Turner, W.A.; Bauin, S. From translations to problematic networks: An introduction to co-word analysis. Soc. Sci. Inf. 1983, 22, 191-235. [CrossRef]

40. Zhang, Y.; Hua, W.; Yuan, S. Mapping the scientific research on open data: A bibliometric review. Learn. Publ. 2018, 31, 95-106. [CrossRef]

41. Klöpffer, W. Life-cycle based methods for sustainable product development. Int. J. Life Cycle Assess. 2003, 8, 157-159. [CrossRef]

42. Klöpffer, W. The role of SETAC in the development of LCA. Int. J. Life Cycle Assess. 2006, 11, 116-122. [CrossRef]

43. Callon, M.; Courtial, J.P.; Laville, F. Co-word analysis as a tool for describing the network of interactions between basic and technological research: The case of polymer chemsitry. Scientometrics 1991, 22, 155-205. [CrossRef]

44. Martínez-Blanco, J.; Lehmann, A.; Chang, Y.J.; Finkbeiner, M. Social organizational LCA (SOLCA)—A new approach for implementing social LCA. Int. J. Life Cycle Assess. 2015, 20, 1586-1599. [CrossRef]

45. De Luca, A.I.; Iofrida, N.; Strano, A.; Falcone, G.; Gulisano, G. Social life cycle assessment and participatory approaches: A methodological proposal applied to citrus farming in Southern Italy. Integr. Environ. Assess. Manag. 2015, 11, 383-396. [CrossRef]

46. Tecco, N.; Baudino, C.; Girgenti, V.; Peano, C. Innovation strategies in a fruit growers association impacts assessment by using combined LCA and s-LCA methodologies. Sci. Total Environ. 2016, 568, 253-262. [CrossRef] [PubMed]

47. Feschet, P.; Macombe, C.; Garrabé, M.; Loeillet, D.; Saez, A.R.; Benhmad, F. Social impact assessment in LCA using the Preston pathway. Int. J. Life Cycle Assess. 2013, 18, 490-503. [CrossRef]

48. Chen, W.; Holden, N.M. Social life cycle assessment of average Irish dairy farm. Int. J. Life Cycle Assess. 2017, 22, 1459-1472. [CrossRef]

49. Pelletier, N. Social Sustainability Assessment of Canadian Egg Production Facilities: Methods, Analysis, and Recommendations. Sustainability 2018, 10, 1601. [CrossRef]

50. Foolmaun, R.K.; Ramjeeawon, T. Comparative life cycle assessment and social life cycle assessment of used polyethylene terephthalate (PET) bottles in Mauritius. Int. J. Life Cycle Assess. 2013, 18, 155-171. [CrossRef] 
51. Teah, H.Y.; Onuki, M. Support Phosphorus Recycling Policy with Social Life Cycle Assessment: A Case of Japan. Sustainability 2017, 9, 1223. [CrossRef]

52. Sajid, Z.; Lynch, N. Financial Modelling Strategies for Social Life Cycle Assessment: A Project Appraisal of Biodiesel Production and Sustainability in Newfoundland and Labrador, Canada. Sustainability 2018, 10, 3289. [CrossRef]

53. Weldegiorgis, F.S.; Franks, D.M. Social dimensions of energy supply alternatives in steelmaking: Comparison of biomass and coal production scenarios in Australia. J. Clean. Prod. 2014, 84, 281-288. [CrossRef]

54. Balasbaneh, A.T.; Marsono, A.K.B.; Khaleghi, S.J. Sustainability choice of different hybrid timber structure for low medium cost single-story residential building: Environmental, economic and social assessment. J. Build. Eng. 2018, 20, 235-247. [CrossRef]

55. Dong, Y.H.; Ng, S.T. A social life cycle assessment model for building construction in Hong Kong. Int. J. Life Cycle Assess. 2015, 20, 1166-1180. [CrossRef]

56. Navarro, I.J.; Yepes, V.; Martí, J.V. Social life cycle assessment of concrete bridge decks exposed to aggressive environments. Environ. Impact Assess. Rev. 2018, 72, 50-63. [CrossRef]

57. Baumann, H.; Arvidsson, R.; Tong, H.; Wang, Y. Does the production of an airbag injure more people than the airbag saves in traffic?: Opting for an empirically based approach to social life cycle assessment. J. Ind. Ecol. 2013, 17, 517-527. [CrossRef]

58. Zanchi, L.; Delogu, M.; Zamagni, A.; Pierini, M. Analysis of the main elements affecting social LCA applications: Challenges for the automotive sector. Int. J. Life Cycle Assess. 2018, 23, 519-535. [CrossRef]

59. Ekener-Petersen, E.; Höglund, J.; Finnveden, G. Screening potential social impacts of fossil fuels and biofuels for vehicles. Energy Policy 2014, 73, 416-426. [CrossRef]

60. Aparcana, S.; Salhofer, S. Application of a methodology for the social life cycle assessment of recycling systems in low income countries: Three Peruvian case studies. Int. J. Life Cycle Assess. 2013, 18, 1116-1128. [CrossRef]

61. Lu, Y.-T.; Lee, Y.-M.; Hong, C.-Y. Inventory Analysis and Social Life Cycle Assessment of Greenhouse Gas Emissions from Waste-to-Energy Incineration in Taiwan. Sustainability 2017, 9, 1959. [CrossRef]

62. Sousa-Zomer, T.T.; Cauchick Miguel, P.A. The main challenges for social life cycle assessment (SLCA) to support the social impacts analysis of product-service systems. Int. J. Life Cycle Assess. 2018, 23, 607-616. [CrossRef]

63. Camilleri-Fenech, M.; Sola, J.O.I.; Farreny, R.; Durany, X.G. A snapshot of solid waste generation in the hospitality industry. The case of a five-star hotel on the island of Malta. Sustain. Prod. Consum. 2020, 21, 104-119. [CrossRef]

64. Jørgensen, A.; Finkbeiner, M.; Jørgensen, M.S.; Hauschild, M.Z. Defining the baseline in social life cycle assessment. Int. J. Life Cycle Assess. 2010, 15, 376-384. [CrossRef]

65. Barney, J.B. Resource-based theories of competitive advantage: A ten-year retrospective on the resource-based view. J. Manag. 2001, 27, 643-650. [CrossRef]

66. Matos, S.; Silvestre, B.S. Managing stakeholder relations when developing sustainable business models: The case of the Brazilian energy sector. J. Clean. Prod. 2013, 45, 61-73. [CrossRef]

67. del Alonso-Almeida, M.M.; Buil-Fabregà, M.; Bagur-Femenías, L.; Aznar-Alarcón, J.P. Shedding Light on Sustainable Development and Stakeholder Engagement: The Role of Individual Dynamic Capabilities. Sustain. Dev. 2017, 25, 625-638. [CrossRef]

68. Gomes Guimarães, A.; Vaz-Fernandes, P.; Ramos, M.R.; Martinho, A.P. Co-processing of hazardous waste: The perception of workers regarding sustainability and health issues in a Brazilian cement company. J. Clean. Prod. 2018, 186, 313-324. [CrossRef]

69. United Nations Environment Programme. Shout It Out: Communicating Products' Social Impacts: A White Paper of the One Planet Network Consumer Information Programme; United Nations: New York, NY, USA, 2018.

70. Russo Garrido, S.; Parent, J.; Beaulieu, L.; Revéret, J.P. A literature review of type I SLCA—making the logic underlying methodological choices explicit. Int. J. Life Cycle Assess. 2018, 23, 432-444. [CrossRef]

71. Sureau, S.; Neugebauer, S.; Achten, W.M.J. Different paths in social life cycle impact assessment (S-LCIA)—A classification of type II impact pathway approaches. Int. J. Life Cycle Assess. 2020, 25, 382-393. [CrossRef]

72. do Carmo, B.B.T.; Margni, M.; Baptiste, P. Customized scoring and weighting approaches for quantifying and aggregating results in social life cycle impact assessment. Int. J. Life Cycle Assess. 2017, 22, 2007-2017. [CrossRef] 
73. Kühnen, M.; Hahn, R. From SLCA to Positive Sustainability Performance Measurement: A Two-Tier Delphi Study. J. Ind. Ecol. 2019, 23, 615-634. [CrossRef]

74. Macombe, C.; Leskinen, P.; Feschet, P.; Antikainen, R. Social life cycle assessment of biodiesel production at three levels: A literature review and development needs. J. Clean. Prod. 2013, 52, 205-216. [CrossRef]

75. Weidema, B.P. The Integration of Economic and Social Aspects in Life Cycle Impact Assessment. Int. J. Life Cycle Assess. 2006, 11, 89-96. [CrossRef]

76. Hutchins, M.J.; Sutherland, J.W. An exploration of measures of social sustainability and their application to supply chain decisions. J. Clean. Prod. 2008, 16, 1688-1698. [CrossRef]

77. Wang, S.W.; Hsu, C.W.; Hu, A.H. An analytic framework for social life cycle impact assessment-Part 1: Methodology. Int. J. Life Cycle Assess. 2016, 21, 1514-1528. [CrossRef]

78. Zimdars, C.; Haas, A.; Pfister, S. Enhancing comprehensive measurement of social impacts in S-LCA by including environmental and economic aspects. Int. J. Life Cycle Assess. 2018, 23, 133-146. [CrossRef]

79. Tallentire, C.W.; Edwards, S.A.; Van Limbergen, T.; Kyriazakis, I. The challenge of incorporating animal welfare in a social life cycle assessment model of European chicken production. Int. J. Life Cycle Assess. 2019, 24, 1093-1104. [CrossRef]

80. Fontes, J.; Tarne, P.; Traverso, M.; Bernstein, P. Product social impact assessment. Int. J. Life Cycle Assess. 2018, 23, 547-555. [CrossRef]

81. Oluić-Vuković, V. Bradford's distribution: From the classical bibliometric "law" to the more general stochastic models. J. Am. Soc. Inf. Sci. 1997, 48, 833-842. [CrossRef]

(C) 2020 by the authors. Licensee MDPI, Basel, Switzerland. This article is an open access article distributed under the terms and conditions of the Creative Commons Attribution (CC BY) license (http://creativecommons.org/licenses/by/4.0/). 